\title{
The Nature of Notebooks: How Enlightenment Schoolchildren Transformed the Tabula Rasa
}

\section{Matthew Daniel Eddy}

\begin{abstract}
John Locke's comparison of the mind to a blank piece of paper, the tabula rasa, was one of the most recognizable metaphors of the British Enlightenment. Though scholars embrace its impact on the arts, humanities, natural sciences, and social sciences, they seldom consider why the metaphor was so successful. Concentrating on the notebooks made and used by the schoolchildren of Enlightenment Scotland, this essay contends that the answer lies in the material and visual conditions that gave rise to the metaphor's usage. By the time students had finished school, they had learned to conceptualize the pages, the script, and the figures of their notebooks as indispensable learning tools that could be manipulated by scores of adaptable folding, writing, and drawing techniques. In this article, I reveal that historicizing the epistemology and manipulability of student manuscript culture makes it possible to see that the success of Locke's metaphor was founded on its appeal to everyday note-keeping activities performed by British schoolchildren.
\end{abstract}

\section{BEYOND THE TABULA RASA}

The tabula rasa is perhaps the best-known metaphor used to describe the minds of young learners during the eighteenth century. It inferred the possibility of achieving a state of filledness, one in which the writtenness of script served both as a form of order and a bearer of meaning. Consequently, in addition to comparing two objects - the mind and a piece of paper-the tabula rasa also compared two modes of interface-thinking and writing. Thinking transformed an empty mind into a filled mind. Writing transformed a blank page into a written page. ${ }^{1}$

For the past two centuries, historians of the arts, humanities, natural sciences, and social sciences have conceptualized the tabula rasa primarily as an object, drawing comparisons between a sheet of paper and other object-based metaphors that liken the mind to a cabinet, theater, room, or a house. ${ }^{2}$ But what if we moved the focus from objects to modes? That is to say, what if we flipped the metaphor so that writing as thinking served as the starting point for understanding the mind as a

This article was written while Matthew Daniel Eddy was a visiting fellow at the Max Planck Institute for the History of Science, Berlin. A very special thanks to Lorraine Daston, Christine von Oertzen, Carla Bittel, Elaine Leong, Beth Yale, and all the members of the Working with Paper research group for commenting on drafts of this essay. Many colleagues in Durham helped him clarify ideas and offered insight into the material and visual culture of manuscript culture, particularly Ludmilla Jordanova, Rachel Dunn, Lenka Sediva, and Laura Dearlove. Helpful manuscript guidance was offered by Ralph McLean and the staff of the National Library of Scotland and Edinburgh City Archives.

${ }^{1}$ Brad Pasanek, Metaphors of Mind: An Eighteenth-Century Dictionary (Baltimore, 2015), 227-48.

2 Pasanek, Metaphors of Mind, 205-26. 
piece of paper? And what if instead of focusing solely on what textbooks said that children should write, we went even further and applied the question to handwritten artifacts actually made and used by schoolchildren?

During the Enlightenment, schoolchildren learned a rich array of techniques that helped them to transform blank sheets of paper into the manuscript pages of a notebook. Whereas historians have given some attention to how textbook authors praised penmanship, ${ }^{3}$ we know very little about how such skills were internalized or applied by school students, particularly by learners whose future professional or domestic duties would require them to move well beyond singular sheets of paper into a world of voluminous, self-organized codices used to order everything from accounts to recipes.

How were the techniques required to make such a sophisticated scribal artifact internalized? This question is particularly relevant to notebooks because of the special role they played in codifying and organizing knowledge systems. Notebooks now receive attention as the informatic precursors to the multimedia forms of interface offered by today's digital culture, leading a number of historians to conceptualize them as paper technologies, or, in the words of Anthony Grafton, magnificent "machines" that operated according to "multiple impure information regimes."4

Far from being mindless acts of replication, molding, writing, and drawing notebook pages were increasingly conceptualized from the seventeenth century forward as a mind-transforming performance. In many respects, the nature of notebooks, like the nature of printed books, was dynamic, in that they were objects that instantiated a process of knowledge in the making. ${ }^{5}$ The rise during the early modern period of notebook usage among the middling classes took place at an important transitional moment. The classical and medieval belief that most things could be held in the memory was giving way to the modern notion that the human mind could no longer hold all of the knowledge being produced by print culture. As Richard Yeo has shown, in addition to being an aid to memory, the notebook became a paper technology that extended the mind. ${ }^{6}$

Focusing on the Scottish Enlightenment, this essay contends that the design and construction of student notebooks can help us to better understand the material and visual preconditions that sustained the developmental resonance of the tabula rasa metaphor. When approached via its eighteenth-century usage, the Latin term tabula invites a dynamic and adaptable conceptualization of the tabula rasa as an interactive learning tool. During the early modern period, this word (and its

\footnotetext{
${ }^{3}$ Aileen Douglas, Work in Hand: Script, Print, and Writing, 1690-1840 (Oxford, 2017); Tamara Plakins Thornton, Handwriting in America: A Cultural History (New Haven, 1998).

${ }^{4}$ Anke Te Heesen, "The Notebook: A Paper-Technology", in Making Things Public, Atmospheres of Democracy, ed. Bruno Latour and Peter Weibel (Cambridge, 2005), 582-89; Anthony Grafton, "The Republic of Letters in the American Colonies: Francis Daniel Pastorius Makes a Notebook," American Historical Review 117, no. 1 (February 2012): 1-39, at 23 and 39.

${ }^{5}$ Here I am referring specifically to the epistemological variations of print culture revealed and historicized in Adrian Johns, The Nature of the Book: Print and Knowledge in the Making (Chicago, 1998). For the epistemological foundations of note-keeping, see Hans-Jörg Rheinberger, "Scrips and Scribbles," $M L N$ 118, no. 3 (April 2003): 622-36; Christoff Hoffmann, "Processes on Paper: Writing Procedures as Non-Material Research Devices," Science in Context 26, no. 2 (June 2013): 279-303.

${ }^{6}$ Richard Yeo, Notebooks, English Virtuosi, and Early Modern Science (Chicago, 2014). For the longstanding relationship between memory and graphic culture, see Douwe Draaisma, Metaphors of Memory: A History of Ideas about the Mind (Cambridge, 2000).
} 
vernacular form, "table") was used to describe any visualization made on a square or rectangular surface (a sheet of paper in this case). ${ }^{7}$ In Britain, schoolbooks regularly used this wider notion of a table until the early nineteenth century. For instance, the Royal Standard Dictionary, a book written by the Edinburgh academy master William Perry and marketed to Scottish schoolchildren, defined "table" as "any flat surface," and "tabular" as an object "formed in squares or plates." At the most basic level, then, every page was a "tabula."

Concentrating on notebooks made by students who attended the schools and academies of eighteenth-century Scotland, I suggest that, in order to organize and codify a codex, young note-keepers needed to learn three core paper-based techniques of interface, each consisting of an integrated set of skills to be learned through iteration. First, there was the technique of molding a sheet into a page, a tabula folia, through acts of folding, cutting, gathering, flattening, and binding sheets into pages. Second, there was the technique of writing a page, a tabula verba, through acts of composing, ciphering, and compositing it into an accessible layout. Third, there was the technique of drawing a page, a tabula figura, through acts of dialing, diagramming, stylizing, and positioning figures.

My conceptualization of a notebook bears many similarities to the ways in which scholars are increasingly characterizing objects and artifacts in relation to their material and visual affordances. In his work on early modern visual culture, for instance, the art historian Michael Baxandall argued that pictures, broadly construed, are best understood as "purposeful" artifacts, as "material and visible deposits left behind by earlier people's activity." Following Baxandall's approach to paintings and their painters, this essay reveals that historians can catch a glimpse of note-keepers' patterns of intention by excavating the techniques they used to make the pages of their notebooks.

Before we delve into how Scottish students acquired purposeful note-keeping techniques, it is necessary to say a few words about how notebooks fit into Scotland's educational system during the long eighteenth century. In most cases, Scottish students started to keep school notebooks after they progressed from a burgh or parish school to an academy, grammar school, or private tutor in their early teenage years. ${ }^{10}$ And while they may also have kept other kinds of notebooks like commonplace books, diaries, or sketchbooks, school notebooks inhabited a specific place in the Scottish educational system. ${ }^{11}$

Though Scottish students kept school notebooks during the entire eighteenth century, most of today's extant specimens were made from the mid-century onward, a state of affairs no doubt linked to changes in primary education that

\footnotetext{
${ }^{7}$ Stephen Ferguson, "Systems and Schema, Tabulae of the Fifteenth to Eighteenth Centuries," Princeton University Library Chronicle 49, no. 1 (Autumn 1987): 9-30.

${ }^{8}$ William Perry, The Royal Standard Dictionary (Edinburgh, 1775), 373.

${ }^{9}$ Michael Baxandall, Patterns of Intention: On the Historical Explanation of Pictures (New Haven, 1985), esp. 13.

${ }^{10}$ The contemporary term used to describe students of this age was "youth"; see s.v., "youth, n.," Oxford English Dictionary Online, http://www.oed.com/view/Entry/232184? redirectedFrom=youth\#eid, accessed 1 November 2017.

${ }^{11}$ For further information on the other kinds of notebooks made by Scottish children (a number of them cited later in this essay), see Matthew Daniel Eddy, “The Child Writer: Graphic Literacy and the Scottish Educational System, 1700-1820," History of Education 45, no. 6 (November 2016): 695-718.
} 
were made in response to the 1745 Jacobite rebellion and the onset of the new educational psychology promoted in the writings of John Locke. ${ }^{12}$ Of the notebooks that have been preserved by the National Library of Scotland and other institutions, a notable number were made by students attending the Edinburgh High School and the Perth Academy - arguably the two most influential schools of the time. ${ }^{13}$ Others were made by tutees who studied with private instructors giving small-group lessons in cities such as Edinburgh, Glasgow, Aberdeen, and St. Andrews. ${ }^{14}$

Scottish school notebooks often were manuscript textbooks that collated what students had copied or learned firsthand. ${ }^{15}$ Keeping this kind of notebook required them to learn a number of graphic techniques that were directly applicable to the scribal demands they would face as literate adults operating in domestic, commercial, military, or academic settings. Once they mastered the techniques required to perform school note-keeping, they were more ready to attend university lectures, become adult note-keepers or even participate in the wider European Republic of Letters.

Whereas historians sometimes conceptualize the manuscript textbook tradition as a form of rote learning, it was common for educators in Scotland, and in the Atlantic world more generally, to treat all forms of writing, including copying and composing, as routines that actively transformed the minds of children. ${ }^{16}$ Students made notebooks with a view to learning the facts, principles, and rules of the subjects that they were studying. Notebooks were also memory devices that helped students to learn and access information on paper. In this sense, they served a similar developmental role as printed textbooks in that they inculcated knowledge and served as material forms of remembering.

The most common subjects recorded in school notebooks were algebra, geometry, trigonometry, "spherics," natural philosophy, geography, Greek, Latin, surveying, gauging, and leveling. But the purpose of keeping a notebook was not solely to record facts. ${ }^{17}$ School notebooks were multipurpose artifacts with uses that extended outside the immediate learning environment. They demonstrated to a fee-paying parent what a student had learned, and they helped erstwhile students remember what they had learned when they became adults. From the perspective of teachers and tutors, school notebooks implicitly served as advertisements for what kind of instruction was on offer, a situation that undoubtedly led educators to seek out

${ }^{12}$ For Locke's impact on Scottish pedagogy, see Matthew Daniel Eddy, "The Cognitive Unity of Calvinist Pedagogy in Enlightenment Scotland," in Reformed Churches Working Unity in Diversity, ed. Ábrahám Kovács (Budapest, 2016), 46-60.

${ }^{13}$ William Steven, History of the High School of Edinburgh (Edinburgh, 1849); William Morrison, ed., Memorabilia of the City of Perth (Perth, 1806).

${ }^{14}$ Most of the notebooks I use are housed in the special collections of the National Library of Scotland (hereafter NLS), Edinburgh City Archive (hereafter ECA), and Edinburgh University Library (hereafter EUL).

${ }^{15}$ Early modern manuscript textbooks are discussed throughout Thomas Knoles, Rick Kennedy, and Lucia Zaucha Knoles, eds., Student Notebooks at Colonial Harvard: Manuscripts and Educational Practice, 1650-1740 (Worcester, MA, 2003).

${ }^{16}$ William Huntting Howell, Against Self-Reliance: The Arts of Dependence in the Early United States (Philadelphia, 2015).

${ }_{17}$ The printed textbooks used to teach these topics are discussed in Alexander Law, Education in Edinburgh in the Eighteenth Century (Edinburgh, 1960); Duncan Kippen Wilson, The History of Mathematical Teaching in Scotland to the End of the Eighteenth Century (London, 1935). 
teaching methods that favored the production of an attractive notebook. But perhaps the most important purpose of school notebooks was the fact that they were the main way that children learned the core writing, drawing, and editing techniques required to set knowledge in motion on and through paper.

\section{MOLDING TECHNIQUES}

At first glance, the adaptability of a notebook page as a jointly material and visual object might not seem that obvious to the twenty-first-century observer. This is mainly because the digital texts that we use today inhabit a different kind of materiality than that which existed during the Enlightenment- a flat materiality that makes it difficult to see that paper can be an epistemic object, that is, a dynamic object that helps to create knowledge. ${ }^{18}$ This factor obscures the "paperness" of predigital notebook pages and the fact that they were temporal objects that were often assembled from different kinds of paper over a period of time. In addition, today's extant school notebooks housed in special collections usually are packaged as leatherbound volumes, giving the impression that the content and order of their pages was fixed at the time of composition and subsequent usage.

But for many school notebooks, nothing could be further from the truth. The notebooks created by Scottish schoolchildren often did not begin as notebooks at all. They began as blank sheets of paper that could be ordered and reordered through folding, bending, creasing, gluing, piercing (with pins), gathering, stacking, shuffling, turning, ripping, scratching (a mode of erasure), sewing, and binding, all according to the child note-keeper's needs as a learner. Though forgotten today, these practices during the early modern period were called "molding" techniques, and they formed the manual and material bedrock of the tabula rasa metaphor, especially as it was formulated by John Locke in his widely read Some Thoughts Concerning Education. In the conclusion, he famously intimated that the mind was a piece of "white paper, or wax, to be moulded and fashioned as one pleases." 19

The rest of this section addresses core paper-molding techniques that schoolchildren learned while making a notebook. Since much work remains to be done on children's manuscript culture in general, it is more of a prolegomenon. Rather than being fixed, each page was a tabula folia, a quadriform, flexible learning device through which students internalized how to use molding techniques to fashion a scribal container, an information management artifact that preserved what they learned in the classroom and served as a form of user training for the many kinds of paper documents they would design or encounter as adults. ${ }^{20}$

To make a blank page, students first had to find and select sheets of paper. Though paper was a ubiquitous medium of communication during the Enlightenment, its

\footnotetext{
${ }^{18}$ The epistemological possibilities of paper tools are foregrounded in Michael Friedman and Wolfgang Schäffner, "On Folding: Introduction of a New Field of Interdisciplinary Research," in On Folding: Towards a New Field of Interdisciplinary Research, ed. Friedmann and Schäffner (Bielefeld, 2016), 7-30; Eric Livingston, Ethnographies of Reason (London, 2008), 89-107. For early modern paper objects, see Anke te Heesen, The Newspaper Clipping: A Modern Paper Object (Manchester, 2014), 15-31.

${ }^{19}$ John Locke, Some Thoughts Concerning Education, 12th ed. (Edinburgh, 1752), 324.

${ }^{20}$ For the historical importance of paper as a form of information management, see Lisa Gitelman, Paper Knowledge: Toward a Media History of Documents (Durham, 2014).
} 
many graphic applications are strikingly absent from the cultural history of predigital Scotland, and of Europe more broadly. Scotland had a healthy paper industry and near the end of the century Edinburgh became a publishing powerhouse. ${ }^{21}$ When it came to educational literature, Scotland's publishers either printed or imported works written by fashionable British pedagogues who stressed the utility of paper devices such as "picture-books," geographical puzzles, and flashcards that contained the alphabet or "the names and pictures" of noteworthy personalities. Yet despite its importance, we are only just beginning to learn about the cultural life of paper in Scotland. ${ }^{22}$

Students kept notebooks for many subjects taught in Scottish schools. Based on the similarity of subjects and layouts that appear in notebooks preserved from schools and academies, students likely copied their notes from exemplar posters, a tradition that was used by Scottish writing masters as well. ${ }^{23}$ They cyphered on loose sheets, or even slates, a practice summed up in 1748 in James Todd's The School-Boy and Young Gentleman's Assistant: "I say he [a student] should have one [geometry book] by him while he Works on his Slate, or his paper, as he has his Grammar by him, for culturing in parsing, \&c. of Language."24 Once committed to paper, these acts of copying and cyphering produced what Scots sometimes called "scroll books," that is, rough notes or draft copies that were then recopied as a neater set of notes at a later date. From the seventeenth to the nineteenth century, the term "scroll book" (also spelled "scrow buik") was used in Scots English to refer to "a school rough notebook." 25 The writing of scroll books occurred at every level of literate society, and as can be seen in those produced by the clerks recording the minutes of Edinburgh City Council, they sometimes existed within a vast system of scribal culture that historians have only begun to understand. ${ }^{26}$

The majority of Scotland's extant school notebooks are recopied manuscripts based on students' scroll books. The writing and drawing techniques practiced by schoolchildren on the pages of scroll books are hard to trace because none have survived. ${ }^{27}$ Based on the scroll books of university students, we can infer safely that those kept by schoolchildren were written on different kinds of loose and bound paper. Making the copied version of the notebook gave young note-keepers the

${ }^{21}$ For Scottish paper and publications industries, see Robert Waterston, "Further Notes on Early Paper Making near Edinburgh," Book of the Old Edinburgh Club 27 (1949): 40-59; Richard B. Sher, The Enlightenment and the Book: Scottish Authors and Their Publishers in Eighteenth-Century Britain, Ireland, and America (Chicago, 2008).

${ }^{22}$ Paper devices were often mentioned by pedagogical authors influenced by John Locke's writings. A prominent Scottish voice on this topic was Henry Home (Lord Kames), Loose Hints upon Education (Edinburgh: 1781), 61-64, 234-35. For the cultural importance of paper in Scotland at this time, see Claire Friend, The Social Life of Paper in Edinburgh, 1750-1820 (PhD diss., University of Edinburgh, forthcoming).

${ }^{23}$ Edmund Butterworth, Universal Penman, or, The Beauties of Writing Delineated (Edinburgh, 1785).

${ }^{24}$ James Todd, The Schoolboy and Young Gentleman's Assistant, Being a Plan of Education (Edinburgh, 1748), 70. Note that, although the "gentlemen" is used in the title, the facts and skills communicated in the book were clearly aimed at middle-class children as well.

${ }^{25}$ Mairi Robinson, ed., The Concise Scots Dictionary (Aberdeen, 1985), 592.

${ }^{26}$ Scroll Council Minutes, c. 1682-1875, Bound MSS, ECA; Final Council Minutes, c. 1682-1875, Bound MSS, ECA. The minutes are uncatalogued and must be recalled from an offsite depository.

${ }^{27}$ One could possibly argue that Peter Purdie's 1823 school notebook is a scroll book. Its provenance, however, is unknown, making it difficult to say what stage of the note-keeping process it represents. Peter Purdie (Notekeeper), "Mathematics," 1823, MS 14288, NLS. 
opportunity to learn how to select and manipulate the kinds of paper required to organize information in different kinds of notebooks. There were, for example, choices to be made regarding the different sizes and brands of paper that might be used. Some students selected quarto sheets with the intent of leaving little white space around their inscriptions and drawings. Others used folio sheets so that they could space out the content. These choices were influenced by a student's finances and remind us that economic restrictions often played a role in the kinds of materials that note-keepers could use to make a notebook.

Two fundamental skills were required to make a tabula folia, that is to say, to mold a sheet of paper into a notebook page. First there was quiring, the ability to shape a sheet of paper into a quadriform format conducive to being a page. Second, there was what might be called "codexing," the ability to gather and fix quires into a book format.

Many student notebooks were made out of folded, unbound booklets called quires (today historians sometimes call them "gatherings"). Constructing a manuscript book via the act of quiring was an established technique reaching back to the codices of the Middle Ages. As noted by codicologists and ethnologists alike, transforming paper (or vellum) into efficiently designed quires required time and skill. ${ }^{28}$ In the case of Scotland's school notebooks, the quiring process began with a student folding a loose-leaf quarto or octavo sheet in half. The product of this kind of folding (bifoliating) was a bifolium (plural, bifolia).

A collection of bifolia laid inside or stacked on top of each other was a quire. Today it would be called an unbound booklet. It was this kind of interchangeable loose-leaf quire that students used to construct a good number of school notebooks, bound and unbound, during the Scottish Enlightenment. Notably, the experience of folding paper in this manner was slightly different from the kinds of folding used to make the printed pages of a book (figure 1). As explained in early modern printing handbooks, compositors intentionally arranged pages out of order on a sheet. Once printed, the sheet was folded in a manner that placed the pages in proper numeric order. $^{29}$ Compared to quiring, this technique made it harder to replace individual printed pages when mistakes were made.

The number of bifolia in a quire depended on the skills and resources of the student. Based on the quires of notes made at Edinburgh High School, it seems the student-made quires were small, ranging from eight to sixteen pages (which were also called forms). ${ }^{30}$ The ability to make paper folds and forms into a quire was an essential technique that had to be learned at some stage by most people who made an early modern notebook. Learning to quire constituted a mode of internalizing a jointly linear and flexible conceptualization of ordered ideas even before they were represented as inscribed facts on paper. The iterative routines required to fold a piece of paper reinforced, for instance, the utility of gestalt principles such as symmetry, perpendicularity, rectilinearity, angularity, and parallelity. Using

\footnotetext{
${ }^{28}$ Steven W. May and Heather Wolfe, "Manuscripts in Tudor England," in A Companion to Tudor Literature, ed. Ken Cartwright (Chichester, 2010), 125-39; Livingston, Ethnographies of Reason, 89-107.

${ }^{29}$ Philip Luckombe, The History of the Art of Printing (London, 1771), 410-38.

${ }^{30}$ Several helpful specimens of pre-bound quires made by students can be found in the Edinburgh High School collection housed in Edinburgh City Archives. For example, see Archibald Cullen, "Translation of English into Latin,” c. 1800, loose-leaf, SL137/9/8, ECA. It consists of several quarto sheets folded into an octavo quire.
} 


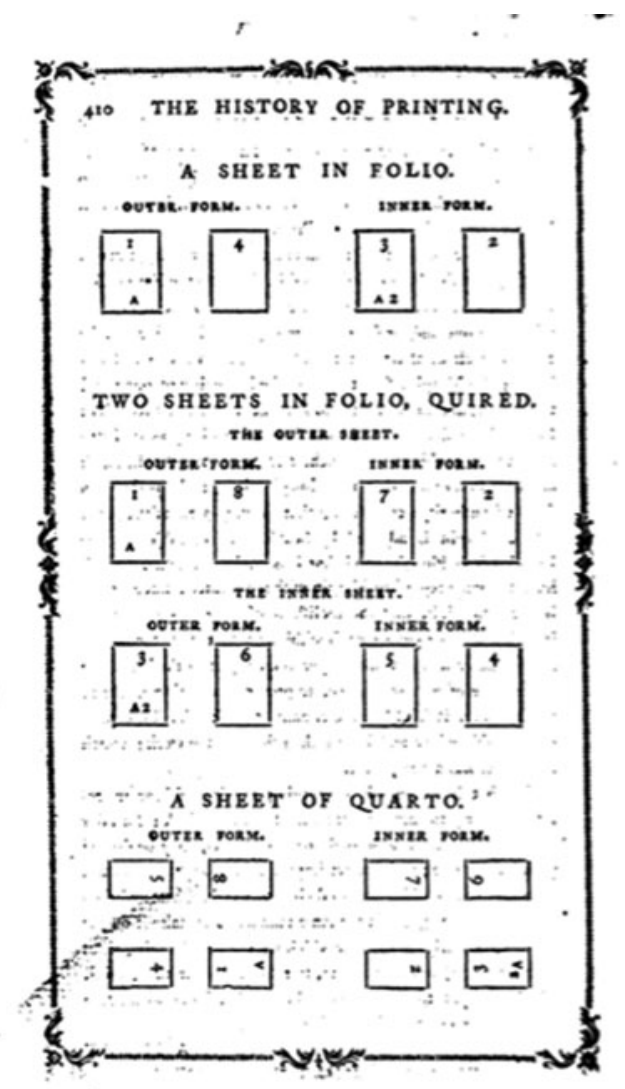

Figure 1-Philip Luckombe, The History of the Art of Printing (London, 1771), 410.

loose-leaf bifolia also made it easier to remove pages that contained mistakes or to shuffle pages into a different order before they were bound. When students shaped and shuffled paper in this manner, they learned that ordering knowledge was a flexible exercise. ${ }^{31}$

Some children gathered their loose-leaf quired notes or assignments and sewed them together. This was the case during the 1780s for William Erskine, an Edinburgh High School student and future orientalist, who sewed a number of his Latin translations into a small notebook ${ }^{32}$ (figure 2). Sometimes students-for instance, the future novelist Sir Walter Scott and the future politician Lord Henry Bougham-simply kept their loose-leaf bifolia exercises unbound, leaving behind

${ }^{31}$ For the gestalt principles of visual culture, see Rudolf Arnheim, Art and Visual Perception: A Psychology of the Creative Eye (Berkeley, 2004); Barbara Tversky, "Visualising Thought," Topics in Cognitive Science 3, no. 3 (July 2011): 499-535.

32 William Erskine, "Latin Exercise Book," 1784, Bound MS, SL137/9/38, ECA. 
helpful evidence of how students designed the kinds of quires that potentially could be made into a notebook. ${ }^{33}$ When considered alongside the other paper-molding techniques mentioned above, the techniques required to manipulate a sheet of paper were evidently just as important as those required to write on it. Some educators recognized the importance of such techniques and integrated them into their pedagogical systems.

The Scottish philosopher, educator, and novelist Elizabeth Hamilton, for example, held that the material facets of books and notebooks were themselves learning tools. In her Letters on the Elementary Principles of Education, she observed, "The leather binding of books, the paper which forms the leaves, the thread on which these leaves are strung, and the characters that are printed on them, may be made instrumental in invigorating the conceptions: and I am persuaded, that habits of attention thus acquired, would be found of greater use in developing the faculties, than any lessons which the poor ignorant children could be made to read, or get by heart." 34 At the time, "conception" and the notion of a mental "faculty" were central components of associationism, an early form of cognitive science. ${ }^{35}$ Like many leading Scottish educational commentators, Hamilton used associationism to frame her pedagogical system. In her view, the material management of paper was itself a cognitive technique, that is, an activity that shaped the memory and created rational capabilities.

In addition to making quires, some schoolchildren purchased blank "paperbooks," which consisted of sheets folded in half and sewn together in the crease. Though seldom studied as an interactive medium that facilitated the management of predigital knowledge, paper-books were sold by most early stationers or booksellers because adults frequently used them to manage domestic, commercial, or artistic information rendered in pen, graphite, or watercolor. ${ }^{36}$ Paper-books were sold in the same sizes as books, but student note-keepers tended to use quarto, octavo, and duodecimo formats. The sewn binding prevented the pages from becoming disordered. Sometimes stationers (and even students) sewed on a piece of flexible cardboard as a cover.

Once students had inscribed their notes on quires or paper-books, they then had to learn how to collate and fix a codex, that is, a manuscript book that, in the case of a notebook, was designed to act as a reference tool. The act of codexing required many skills, particularly since most school notebooks were assembled over months and sometimes years. The notebooks were bound in a variety of formats that ranged

${ }^{33}$ Walter Scott, "Translations of Latin into English and English into Latin," c. 1800, loose-leaf sheet, SL137/9/29, ECA; Henry Brougham, "Translation of English Phrases into Latin," 8 October 1790, loose-leaf sheet, SL137/9/3, ECA. See also the translations of Archibald Cullen that consist of two quarto sheets folded into an octavo booklet of four pages. Cullen, "Translation of English into Latin."

${ }^{34}$ Elizabeth Hamilton, Letters on the Elementary Principles of Education, vol. 2, 5th ed. (London, 1810), 251-52.

${ }^{35}$ The centrality of "conception" is most clearly summarized in the Edinburgh lectures of Dugald Stewart, Elements of the Philosophy of the Human Mind (Edinburgh, 1792), esp. 132-50.

${ }^{36}$ The uses and prices of Scottish paper-books remain relatively understudied. A good indication of their price and popularity are the sales ledgers of the Edinburgh stationer Charles Elliot; see Elliot, "Ledger 1," 1771-77, John Murray Archive MS 43098, NLS. See also Stephen W. Brown, "Paper Manufacture," in The Edinburgh History of the Book in Scotland, ed. Stephen Brown and Warren McDougal, vol. 2, Enlightenment and Expansion, 1707-1800 (Edinburgh, 2011), 61-64. 


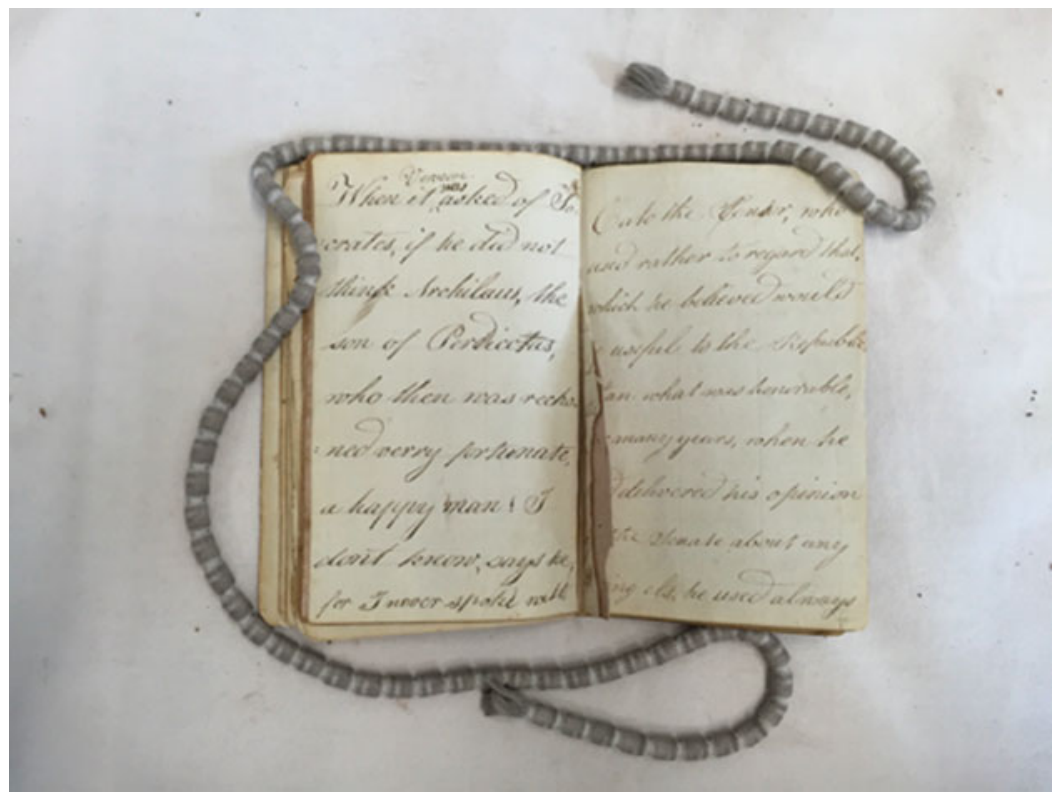

Figure 2-William Erskine, "Latin Exercise Book," 1784, Bound MS, SL137/9/38, CA.

from simple stitches of string to elaborate leather bindings. ${ }^{37}$ Sometimes blank pages were bound at the front or end for future use. ${ }^{38}$ Close inspection of the watermarks, pagination, and bindings of the paper inside school notebooks reveals that many of them are composites - collocations of several sets of copied notes kept by children at different times in different courses.

Rather than recopying their notes all at once from start to finish in a bound, blank volume, many students assembled their bound compendia from a collection of paperbooks or quires. ${ }^{39}$ The placement of the paper in school notebooks with cracked, split, uneven, ripped, or loose bindings further indicates that the techniques of assembly were contingent upon the learning needs of the note-keeper. Likewise, though the order of the pages (and, hence, the subsequent content) was relatively set after it was made, students were presented with further opportunities to order what they had written when the time came to bind all their completed paper-books into

${ }^{37}$ Records of Scottish bookbinders from this period have not survived. William Zachs, "Bindings," in Brown and McDougal, Edinburgh Book History of Scotland, 2:65-69. For England, see Jonathan E. Hill, "From Provisional to Permanent: Books in Boards, 1790-1830," Library 21, no. 3 (September 1999): 247-73.

${ }^{38}$ The technique of inserting blank pages in early modern books and notebooks was commonly practiced by adults. See Jonathan Gibson, "Casting Off Blanks: Hidden Structures in Early Modern Paper Books," in Material Readings of Early Modern Culture, ed. James Daybell and Peter Hinds (Basingstoke, 2010), 208-28.

39 The term "paper-book" was used regularly during the eighteenth century to refer to blank, bound writing books. The term "quire" was used to refer to foldings of unbound paper. See the entries for "paper-book" and "quire" in the OED. 
Table 1-The Four Sets of Paper-book Notes in James Fowler's Schoolbook of 1780

\begin{tabular}{|c|c|c|c|c|c|}
\hline $\begin{array}{l}\text { Year } \\
\text { written }\end{array}$ & $\begin{array}{l}\text { Order in the } \\
\text { notebook }\end{array}$ & Subjects & $\begin{array}{l}\text { Original } \\
\text { pagination }\end{array}$ & $\begin{array}{l}\text { Secondary } \\
\text { pagination }\end{array}$ & $\begin{array}{l}\text { NLS } \\
\text { pagination }\end{array}$ \\
\hline 1780 & 4th & $\begin{array}{l}\text { Composition and } \\
\text { translation }\end{array}$ & $1-47$ & None & $\begin{array}{l}137 \text { recto- } \\
159 \text { verso }\end{array}$ \\
\hline c. $1782 / 3$ & lst & $\begin{array}{l}\text { Arithmetic and } \\
\text { algebra }\end{array}$ & $1-136$ & None & $\begin{array}{l}1 \text { recto- } \\
66 \text { verso }\end{array}$ \\
\hline c. $1782 / 3$ & 2nd & Advanced algebra & $1-98$ & None & $\begin{array}{l}67 \text { recto- } \\
107 \text { verso }\end{array}$ \\
\hline 1784 & $3 \mathrm{rd}$ & Trigonometry & $5-52$ & $99-158$ & $\begin{array}{l}108 \text { recto- } \\
136 \text { verso }\end{array}$ \\
\hline
\end{tabular}

one leather-bound volume. Such compendia could be made immediately after a schoolchild's studies were completed or at a later date.

The four different sets of paper-books bound in the "Schoolbook" of the student James Fowler during the 1780s indicate that notes were not always bound in the order that they were written. Fowler lived in the Strathpeffer area of northwest Scotland and possibly attended school in Fodderty. As shown in table 1, though Fowler's "Schoolbook" is a single volume today, it was originally four paper-books kept over a period of four years. ${ }^{40}$ Once these were bound together as a manuscript book, they ceased to be individual volumes and became sections. In many cases their earlier status of paper-books was all but erased when binders trimmed their edges to form one unified volume. ${ }^{41}$

This transformation of printed paper-books into sections of larger books was a crucial knowledge management technique of the time used by adults to organize the large systems of printed and inscribed knowledge created to teach university students. ${ }^{42}$ But the material structure of Fowler's notebook shows that schoolchildren were learning to practice this ordering technique as well, albeit on a smaller scale. Fowler chose to order his paper-books topically, placing the mathematics sections first and the composition section last (see table 1). But of course this technique of ordering paper-books, essentially an extension of what Walter Ong once called topical logic, was a flexible process and could have been done differently had Fowler decided that the composition section was the most important. ${ }^{43}$ Overall, shuffling

\footnotetext{
${ }^{40}$ James Fowler, "Schoolbook of James Fowler," 1780, Bound MS, MS 14284, NLS. For a set of bound notebooks that were also compendia assembled from a collection of smaller notebooks, see I. M. (Notekeeper), "Perth Academy Notebooks, 3 Volumes," 1787, Bound MSS, MS 14294-6, NLS.

${ }^{41}$ School exercise notebooks were often assembled from collections of paper-books as well. For comparison, see Alexander Kincaid, "Latin Exercise Book," 1764, Bound MS, SL137/9/37, ECA; kept at Edinburgh High School. The cracked binding reveals that it first consisted of exercises recopied on individual paper-books that were eventually bound together.

${ }^{42}$ Matthew Daniel Eddy, "Tools for Reordering: Commonplacing and the Space of Words in Linnaeus's Philosophia Botanica," Intellectual History Review 20, no. 2 (June 2010): 227-52.

${ }^{43}$ Ong held that topical logic was a mode of classifying that grouped things according to convenient "topics" (Greek: topoi; Latin: loci) and not necessarily according to natural kinds. Walter J. Ong, Ramus, Method, and the Decay of Dialogue: From the Art of Discourse to the Art of Reason (Chicago, 2004).
} 


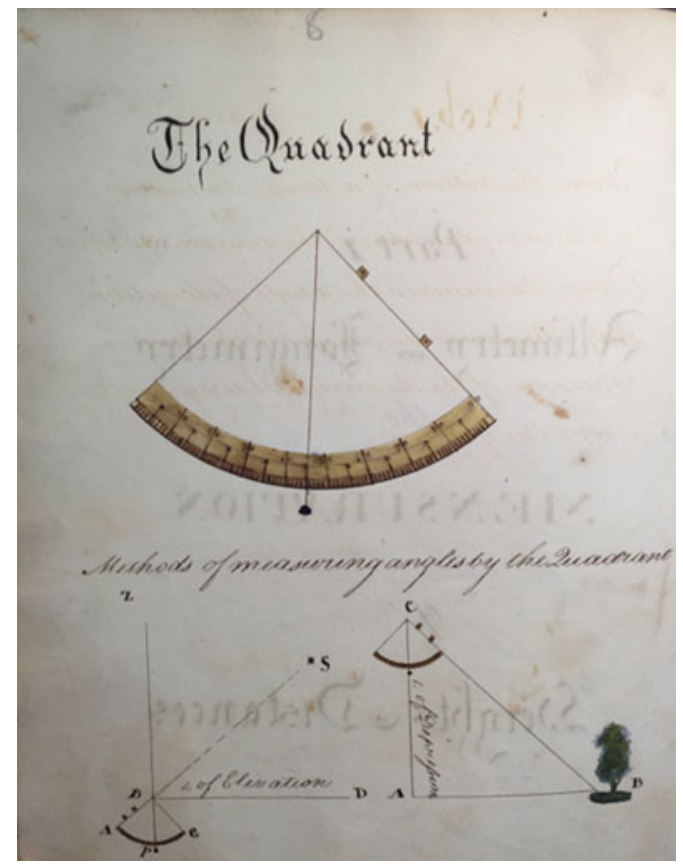

Figure 3-"Practical Mathematics," 1804, Bound MS, 14285, NLS, fol. 6.

paper-books in a topical manner was an important manuscript management technique that allowed students to order their notebooks in a manner they found most useful.

Attending to the many skills associated with quiring and codexing notes foregrounds aspects of note-keeping that directly affected the ways in which students were able to composite words and lines on the page. For instance, as we will see later in this essay, students sometimes drew figures in their notebooks (figure 3). The practice worked in close conversation with the paper techniques used to assemble a student notebook. The best way to draw straight or curved lines, for example, was to inscribe them on a flat surface. In a thick, leather-bound notebook, the binding forced the pages to curve outward in a way that made it difficult to render a straight line with a ruler or a curved line with a compass. Using the flat sheets of paper in a paper-book or quire in the pre-bound stage of the notebook eliminated this problem. Since quires were unbound, each page could be laid out flat. Though paper-books were usually bound, they were thin, running between twenty and forty pages, and usually did not have boards. Because they were a single set of folded sheets, they naturally sat together and only required one or two stitches. All of these characteristics made it easy to press the paper-book open so that it lay flat, thereby making it possible to draw accurate figures.

That notebooks were made up of discrete, rearrangeable sheets of paper introduced an element of adaptability into the learning routines that influenced how children conceived and used a school notebook before and after it was bound. From the very start of the note-keeping process, even before students began to write, the paper 
was formatted as an orderly material. It was sold as a quadriform sheet, that is, a symmetric geometric shape. Students then created pages by folding sheets in half into a bifolia. Like the act of reading words, this act of folding paper imbued various kinds of meaning that made sense to the "foldmaker." The haptics of the technique facilitated an act of visual order that allowed students to begin to think about the material strictures and possibilities presented by a blank sheet of paper, transforming the page into a device, a tabula folia, intended for organizational activities. ${ }^{44}$

The transitive affordances of paper led some during the eighteenth century to see a collection of sheets or bifolia as a "machine." 45 The loose-leaf nature of quires and the mobility of pre-bound paper-books also meant that both could be moved and ordered in ways that fitted the note-keeper's needs. The moveable nature of paper in the hands of schoolchildren created a situation in which the pages of a prebound school notebook rendered it an information management device, a paper machine. As shown in Markus Krajewski's work on the history of index cards, paper machines were part and parcel of the early modern world of predigital media. When individual paper storage devices were manipulated in concert over time, explains Krajewski, "The force taking effect is the user's hand." The movement of the sheets in this manner produces "a mechanical work taking place under particular conditions." 46 Like a pile of index cards, these preassembled quires or paperbooks functioned collectively as a paper machine because they allowed schoolchildren to shuffle information into an ordered thinking device as they were creating it.

School notebooks continued to function as paper machines after they were bound. When students used their notebooks after they finished a course or finished school, they did not necessarily have to move through the pages one after another from start to finish. As the makers of their own notebooks, they were already familiar with the order of the subjects. They could dip about and jump from one part or page to the next as necessary, creating their own order within the post-bound pages whenever they used it. From this perspective, the fixed order of the pages did not always matter, and the contents could be used in whatever order the note-keeper saw fit to create. Thus, even after they were bound, school notebooks functioned as organized but adaptable collections of knowledge. Like manuscript commonplace books, they were, in the words of Anthony Grafton, "informationretrieval machines." 47

There was a final characteristic inherent to the media of paper that allowed students to use school notebooks in a self-directed, interactive manner. As I explain in

${ }^{44}$ For more on the meaningfulness of folding, see Jacques Derrida, Paper Machine (Stanford, 2003), $11-13$.

${ }^{45}$ The "machineness" of paper seems to have been recognized in a variety of contexts. Women in colonial America, for example, described the paper fan, a fashionable object at the time, as a "little gay fluttering machine." Susan M. Stabile, Memory's Daughters: The Material Culture of Remembrance in EighteenthCentury America (Ithaca, 2004), 155-57.

${ }^{46}$ Markus Krajewski, Paper Machines: About Cards and Catalogues, 1548-1929 (Cambridge, MA, 2011), 7. For the use of slips or sheets as information management devices, see also Staffan MüllerWille and Isabelle Charmantier, "Natural History and Information Overload: The Case of Linnaeus," Studies in History and Philosophy of Biological and Biomedical Sciences 43, no. 1 (March 2012): 4-15.

${ }^{47}$ Grafton, "The Republic of Letters in the American Colonies." The comparison of commonplace notebooks to "information-retrieval machines" occurs across pages 5-6. Similar mechanical metaphors occur on page 8 ("information-recovery machine") and 23 ("information-management machines"). 
the following sections, students designing mathematics, navigation, gauging, and leveling notebooks often included technical figures as illustrations. Within this tradition, they rejected the widespread textbook practice of collating figures on one plate because it forced them to constantly turn between the figure and the narrative that explained its use and meaning elsewhere in the book. Student note-keepers frequently drew figures on the page beside or below the narrative that explained how to use or interpret them. Children who made poetic notebooks also employed this user-friendly technique by including vignettes of the scenes they were describing. 48 This proprioceptive technique was yet another important form of knowledge in motion that allowed students to transform a sheet of paper into a tabula folia, a page molded in a manner that was easy to use as an accessible storage device. Situating the figures in such a way enabled them to learn how to see that the relationship between representing and understanding was interactive and often intimately linked to where script and figures were placed within a notebook.

\section{WRITING TECHNIQUES}

Enlightenment historians have traditionally treated writing as a fixed object on paper. But what about the performative aspect - the "writtenness" - of writing? More specifically, what were the techniques of writing, the modes through which the pen was put to paper? How can they be used to understand the ways in which students were taught to conceptualize writing as they transformed the tabula folia into a tabula verba, a written page? For literate Scottish children, writing was an activity that occupied much of their daily life. In addition to functioning as a mode of recording information, it functioned as a mode of learning in its own right. The cultural historian Michel de Certeau underscored this jointly developmental and performative facet of writing when he observed, "In front of his blank page, every child is already put in the position of the industrialist, the urban planner, or the Cartesian philosopher-the position of having to manage a space that is his own and distinct from all others and in which he can exercise his own will."49

If, like de Certeau, we wish to historicize the acts of writing performed on a tabula folia, then we must pay closer attention to how they were being learned or even theorized at any given point in the past. As we saw with Elizabeth Hamilton's comments on the material importance of molding paper, Scottish pedagogues explicitly discussed such performances. They did so mainly because the act of writing occupied a special place in the cognitive models they used to understand the mind.

From the mid-century forward, many educators in Scotland and other parts of Britain interpreted the performativity of writing via an associationist educational psychology that drew strong links between visual and mental order. ${ }^{50}$ The influential philosopher and mathematician Dugald Stewart articulated this long-standing view in

${ }^{48}$ John Black, "Juvenile Poetic Works of John Black," vol. 2, 1797-98, Bound MS, MS.14233, NLS.

${ }^{49}$ Michel de Certeau, The Practice of Everyday Life (Berkeley, 2011), 134.

${ }^{50}$ Alan Richardson, Literature, Education, and Romanticism: Reading as Social Practice, 1780-1832 (Cambridge, 1994), 127-42; Andrew O'Malley, The Making of the Modern Child: Children's Literature and Childhood in the Late Eighteenth Century (London, 2003), 86-101; Sarah Winter, The Pleasures of Memory: Learning to Read with Charles Dickens (New York, 2011), chap. 1. 
the moral philosophy lectures that he gave at the University of Edinburgh in the 1790s. Like many educators of the time, he conceptualized the page of a notebook as a picture that both visualized and influenced how ideas were organized in the mind.

As Stewart's comments on commonplace note-keeping indicate, ordering a notebook through writing was not an inconsequential act. In his words, "A COMMONPLACE [note]book, conducted without any method is an exact picture of the memory of a man whose inquiries are not directed by philosophy. And the advantages of order in treasuring up our ideas in the mind, are perfectly analogous to its effects when they are recorded in writing." ${ }^{1}$ Since everyone's mind was different, note-keepers had to judge for themselves which form of commonplace ordering best served "their own peculiar habits of association and arrangement." 52

The original audience for Stewart's lectures were the teenaged boys who had learned to write and rewrite notebooks in Scotland's schools and academies. During their schooldays they had learned scholarly recording techniques, their "methods," in Stewart's terminology, that enabled them to create a useful school notebook. Perhaps the most important techniques were those that allowed them to structure the layout of the page into a format that helped them to observe what they were writing as they wrote-an act that transformed the page into a visual object, a verbal picture, that was easy to use.

Scotland's schoolchildren used two visual structures to organize the space of their notebook pages: the module and the matrix (figure 4). At the most basic visual level, a module consisted of a heading, usually centered, followed by a block of narrative formatted as a sentence or paragraph. This module could be used to structure one page, or it could be designed to run across two facing pages. ${ }^{53}$ The module emerged as an important information management structure in European medieval codices after scribes began inserting blank spaces between words. ${ }^{54}$ Early modern Scottish schoolchildren used the module to structure the pages of their notebooks. Less often they used a matrix, which divided the page into two columns so that it became a simple word or number table.

Since the mise-en-page techniques required to make a module or matrix were not necessarily subject specific, they were transferable and could be employed across the pages of all the notebooks kept by a student. Put more plainly, they formed the visual basis of notebooks kept for subjects that today would be classified as the arts, humanities, and sciences. Stewart's comments, when considered in tandem with the orderly layouts evinced in school notebooks, entailed the assumption that the writing techniques used to structure blank notebook pages were just as important as the factual content that they preserved.

Once written, modules and matrices became graphic containers, visual sorting tools, in which students efficiently processed and stored information. As the social

51 Stewart, Elements of Philosophy, 423.

${ }^{52}$ Ibid., 441. The order of the written page captured the attention of many Enlightenment educators, including Immanuel Kant at the University of Königsberg. See Kant, "On the First Ground of the Distinction of Regions in Space," The Philosophy of Right and Left: Incongruent Counterparts in the Nature of Space, ed. James van Cleve and Robert E. Frederick (Dordtrecth, 1991), 27-33, esp. 29.

${ }^{53}$ James Fowler of Strathpeffer, for instance, turned both the verso and recto pages into one unified module. Fowler, "Schoolbook," fols. 69v-70r.

${ }^{54}$ Paul Saenger, Space between Words: The Origins of Silent Reading (Stanford, 1997). 

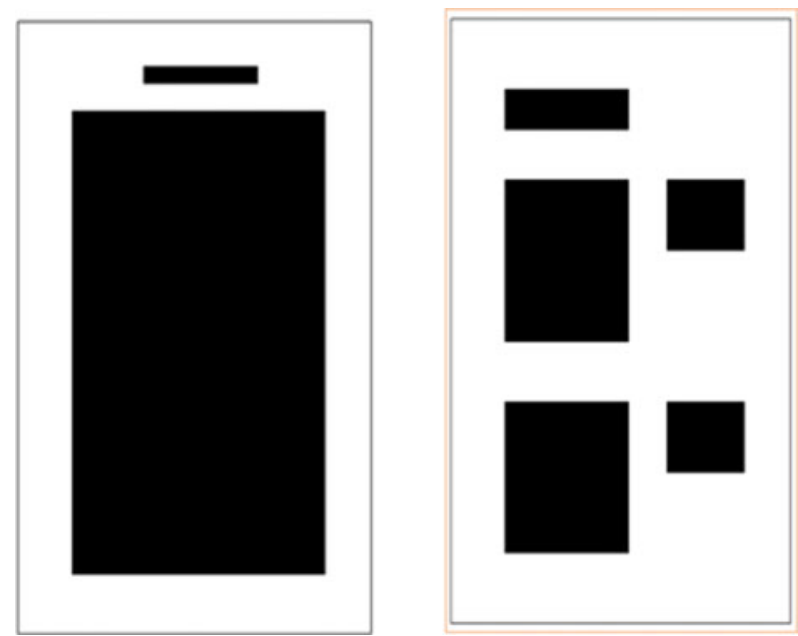

Figure 4-(Left) Stylized Module. Word modules in student notebooks were formed of one column. They contained a heading (sometimes centered), a block of text, and a white frame created by margins. The modules could be short or long, on one page or run over several pages. Sometimes one module ran over two facing pages (see figure 5). The textual block could contain letters or numbers. (Right) Stylized Matrix. Word matrices in student notebooks were formed of two columns. The left column often appeared as a module. The right column usually contained a heading and a notable amount of blank space. The matrix was surrounded by a frame of blank space as well. The visual properties of the modules and matrices transformed them into simple, gestalt images.

anthropologist Jack Goody has shown, in the development of Western culture, tables of this nature played a central role, especially those that were structured as "a matrix of vertical columns and horizontal rows." 55 In addition to structuring the page as two columns, students were at times asked to write multi-columned matrices in practical mathematics courses; the 1710 notebook of schoolboy James Dunbar also reveals that they were used for literary topics as well. ${ }^{56}$

Ever since medieval times, modules and matrices had served jointly as information management tools and as a mode of interface between users and the texts. ${ }^{57}$ In other words, they were stable mise-en-page technologies that had been successfully usertested over the past thousand years. Still, these long-standing technologies had to be learned, adapted, and valued anew by every student note-keeper in accordance with the institutions in which they put pen to paper on a daily basis. Notably, the capability to make and use script as a matrix or module created the capacity to order and sort knowledge in an efficient way that could be applied to any school subject and to later numerous mercantile, academic, and personal uses.

55 Jack Goody, The Domestication of the Savage Mind (Cambridge, 1977), 53.

56 James Dunbar, "A Volume Completed by James Dunbar in 1710 Containing Arithmetic, Introduction to Algebra, and a More Compendious Way of Writeing Than Ordinar Called the Short Hand, Making Use of Farthing's Alphabet," 1710, Bound MS, Acc. 5706/11, NLS.

${ }^{57}$ Hannah B. Higgins, The Grid Book (Cambridge, MA, 2009). 


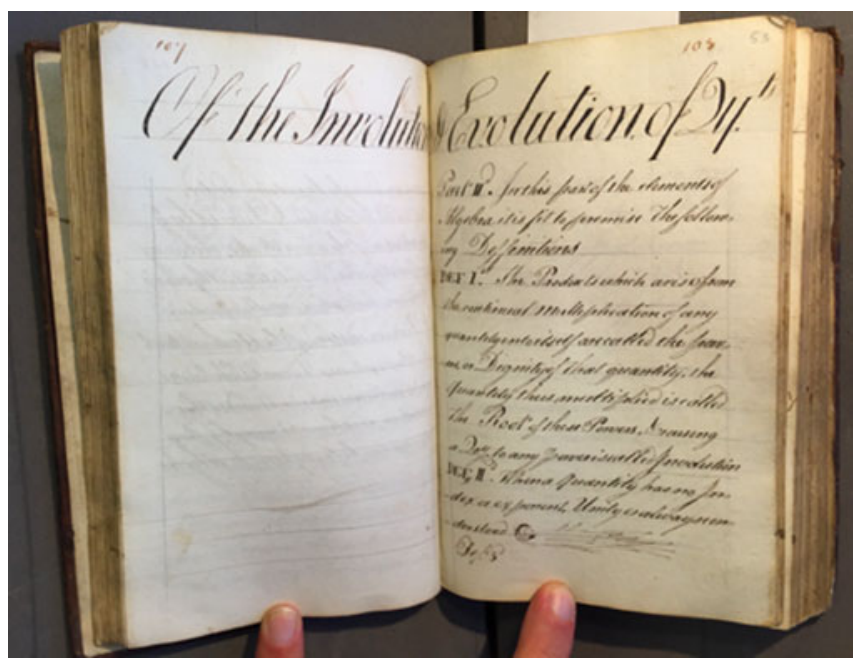

Figure 5-A word module spread across two notebook pages. James Fowler, "Schoolbook of James Fowler," 1780, Bound MS, MS 14284, NLS, fols. 52v-53r.

Young note-keepers were of course exposed to modules and matrices via their regular appearance in textbooks, which were usually laid out in a modular format; ${ }^{58}$ matrices also appeared regularly. Printed compendia featured tables of comparative weights, measures, and prices. ${ }^{59}$ Practical mathematics primers gave tables of "powers" (squared, cubed, and biquadrated) and logarithms used by surveyors, levelers, gaugers, and navigators. ${ }^{60}$ Grammars featured vocabulary, conjugation, and declension tables, and geography primers presented tables of countries and cities. ${ }^{61}$ The rows and columns of these tables required vertical and horizontal reading skills, a mode of interface that Lorraine Daston has called "right-angle reading."62 Such skills had to be learned, and to some children they did not come

${ }^{58}$ Scotland's textbooks are reviewed in Law, Education in Edinburgh; Wilson, History of Mathematical Teaching in Scotland; Ian Michael, The Teaching of English: From the Sixteenth Century to 1870 (Cambridge, 1987).

${ }^{59}$ See the weights and measures conversion tables in the many Edinburgh editions of George Fisher, The Instructor: Or, Young Man's Best Companion (Edinburgh, 1799). For a representative example, see the tables, pp. 70-80. See also David Ramsey, The Weaver and Housewife's Pocket-Book (Edinburgh, 1750).

${ }^{60}$ George Fisher, The Instructor; or Young Man's Best Companion (Edinburgh, 1763), 323-27; E. Hoppus, Practical Measuring Made Easy to the Meanest Capacity, 15th ed. (Edinburgh, 1799); Alexander Ewing, A Synopsis of Practical Mathematics (Edinburgh, 1771); William Panton, The Tyro's Guide to Arithmetic and Mensuration (Edinburgh, 1771).

${ }^{61}$ Grammatical declension schemes occur throughout Alexander Adam, Rudiments of Latin and English Grammar (Edinburgh, 1786); Thomas Ruddiman, Rudiments of the Latin Tongue (Edinburgh, 1779). Good examples of geographic tables occur in Fisher, The Instructor (1763), 265-96; John Mair, A Brief Survey of the Terraqueous Globe (Edinburgh, 1775). All these texts were popular and went through multiple editions.

${ }^{62}$ Lorraine Daston, "Super-Vision: Weather Watching and Table Reading in the Early Modern Royal Society and Academie Royale des Sciences," Huntington Library Quarterly 78, no. 2 (July 2015): 187215 , at 205 . 
easily. Likewise, though it might have been easy for some to read modules and matrices in printed books, designing one in a notebook was much more difficult and required a host of different scribal skills. This was especially the case for younger students who were learning penmanship and bookkeeping, or for students whose previous education had not provided them with the time or materials required to perfect the art of making a module or matrix.

Students sometimes combined modules and matrices into visual forms that suited their own needs. As figure 5 shows, James Fowler, encountered in the previous section, fused two open-faced notebook pages (verso and recto) into a singular module under one heading. He then used each page as a column, effectively creating a matrix. Throughout the notebook, both pages contain script; however, I have chosen this specimen because the empty page makes it easier to see the graphite grid that he first drew to create a unified structure across two facing pages. Once the grid was in place, he then used his impressive chirographic skills to make the heading and subheadings and the prose. ${ }^{63}$ Though Fowler achieved a sophisticated layout, many student note-keepers drew graphite grids before they put pen to paper.

Structuring the space of the written page as a verbal picture, a tabula verba, was a capability-building exercise. It served as a form of visual training that strengthened the proprioceptive relationship between mind and hand. It reinforced the utility of information being arranged via the graphic principles of symmetry, perpendicularity, rectilinearity, angularity, and parallelity. It enabled students to learn how to adapt tabular formats to fit their needs and to adjust and spatially reposition headings, keywords, paragraphs, rows, and columns in a manner that instilled the ability to create a combinatorial word scheme on their own. ${ }^{64}$ Within these forms, clusters of words like headings and paragraphs functioned jointly as carriers of units of information and as cues that helped to visually order their notebook pages. Correspondingly, the abilities required to design such modules and matrices constituted a set of alignment techniques, transforming the student note-keeper into a scribal compositor. As revealed in figure 5, such mise-en-page techniques included everything from structuring the margins and sentence lines with graphite grids to navigating the centering and indenting patterns used to plot headings.

The compositing techniques that students used to inscribe every page of a notebook were nuanced, required training, and would have presented challenges for those who experienced developmental reading or writing difficulties. Needless to say, the process often ended in frustration. A striking case of scribal irritation is evinced in a matrix of shorthand symbols drawn by James Dunbar in his school notebook. He drew the lines of his columns so unevenly that many of them simply ran off the page, rendering the right side of his table useless. Dunbar became so annoyed with his unsuccessful effort that he wrote in the space of a malformed (and hence unusable) column: "I am angry that I left a blank here and wrote filthy Scribble

${ }^{63}$ Fowler, "Schoolbook," fols. 52v-53r.

${ }^{64}$ For early modern word-based combinatorics, see Francis A. Yates, The Art of Memory (London, 1966); Wilhelm Schmidt-Biggemann, Topica universalis: Eine Modellgeschichte humanistischer und barocker Wissenschaft (Hamburg, 1983). For an example of combinatorics during the eighteenth century, see Grafton, "The Republic of Letters in the American Colonies," 25. 
Scribble on the side and that I did not contrive it better." 65 Here we can see that "right-angle writing" was an acquired technique.

Dunbar's case reveals that in order to write within a module or matrix, schoolchildren had to learn how to materially interface with paper through the act of writing. Moving the tip of the pen across paper was not a straightforward task, especially when it came to inscribing neat, curved letters. Early modern paper was made from pulped linen, rendering it thicker than modern paper and prone to grabbing the tip of the pen as a child drew the curved lines of letters and figures. Add to this the fact that linen pulp was strained and dried into paper inside gridded sieves that created parallel microgrooves called chain lines. A blank piece of paper, therefore, was not blank or smooth.

The microgrooves affected how some students used the pen to interface with paper. Depending on how the paper of a notebook was cut by a stationer, the grooved lines ran across the entire surface of the page in either an up-and-down or right-and-left pattern. In some cases, the rectilinear structure of the grooves made it easier to draw a grid, or attempt to write straight sentences freehand, or form the edges of margins. However, the grooves could also present challenges to inexperienced note-keepers. Hitting them the wrong way, for example, could jolt a student's stroke, making the line of a letter or figure uneven or filled with small deviations. This jointly material and visual aspect of the blank page as a tabula rasa, or even a tabula folia, governed how student note-keepers interfaced with the blankness of paper, especially when they endeavored to make a tabula verba.

The evenness of the script in many notebooks shows that students were remarkably adept at making well-formed letters across the textured surfaces inside the space of columns, rows, and paragraphs. Some students even accomplished this feat on poorly bonded paper or on the rough paper covers that protected some paperbooks. The Edinburgh high-school student William Erskine, whom we have already encountered, managed to write his Latin translations in a good hand over the coarse surface of his cardboard notebook cover when he ran out of paper. ${ }^{66}$ As evinced in the scraps of notes kept by the Scottish naturalist Robert Brown in Australia and in the letters written by wives of Scottish merchants and diplomats living in India, the capability to write well even with poor materials was essential for those who needed to record or organize information outside the comfort of their study. ${ }^{67}$

One of the main tasks of a writing instructor was to teach students how to structure the space of a blank page into a layout, usually a module, into which words or numbers could be written. This process of graphic design required a number of writing instruments that were used through a variety of techniques. Unlike today's disposable pens and pencils, the quills and ink used by Enlightenment students

${ }^{65}$ Dunbar, "A Volume Completed by James Dunbar," 1710. For further treatment of the Dunbar notebook and its visual context, see Matthew Daniel Eddy, "The Shape of Knowledge: Children and the Visual Culture of Literacy and Numeracy," Science in Context 26, no. 2 (June 2013): 215-45.

${ }^{66}$ Erskine, "Latin Exercise Book," 1784. The notebook consists of several quires sewn together inside a paper cover.

${ }^{67}$ D. T. Moore and M. A. Beasley, "The Botanical Manuscripts of Robert Brown," Archives of Natural History 24, no. 2 (July 2010): 237-80. The letter-writing skills of Scottish women abroad are addressed throughout Emma Rothschild, The Inner Life of Empires: An Eighteenth-Century History (Princeton, 2011); Maya Jasanoff, Edge of Empire: Lives, Culture, and Conquest in the East, 1750-1850 (New York, 2006). 
required more attention both in terms of making them and using them. Very likely, some students had to make their own quills by gathering suitable feathers (typically from geese, but also crows) and then "dutching" them, usually by curing them in hot sand, to harden the nib. ${ }^{68}$ Since the tips of homemade and store-bought quills came unsharpened, students also had to learn to use penknives. If the nib was misshapen, the ink could disfigure the page through blotting, or it could distort the lines of the letters, making them thick and hard to read. ${ }^{69}$

Other basic instruments included graphite pencils for ruling sentence lines and margins, gum for rubbing out graphite, razors for scraping off words written in ink, and powder for drying (pouncing) the ink. After learning the skills of ruling, rubbing, scraping, and pouncing, some students also learned to design modules through the use of "lead pens" or "tracers," that is, pens with hard metallic tips that impressed a ruled grid into the fabric of the paper ${ }^{70}$ (figure 6). The resulting lines then served as the basis for plotting words and making tables. In short, transforming the blank page into a module or matrix of words, a tabula verba, required training and practice.

The instruments, materials, and techniques necessitated by writing rendered it an activity in which child note-keepers became mindful choreographers of their own scribal performance. Put another way, it would have been very difficult to form letters, plot headings, draw sentence lines, demarcate margins, align columns, or cross-align rows without observing the movement of the hand across the page. Nor would it have been possible to sharpen quills, pounce the page, scratch out mistakes, or even make (or select) ink without being an observer of one's own writing. It was for this reason that instructors encouraged children to treat the act of writing as a form of rational observation.

The teaching handbook used by Edinburgh's Merchant Maiden Hospital for girls, for example, gave the following advice to its writing instructors: "Here you copy three or more letters, but be at great pains to cause them [to] keep the distance equal, and to observe the shape of the letters." Likewise, when demonstrating how to make a pen from a quill, the school's teachers were to ensure that the girls knew how to "observe the method of one who makes a pen well, and endeavor to imitate it."7l Penmanship textbooks made similar connections between the act of writing and the act of observing. ${ }^{72}$

Accordingly, the writing techniques that underpinned the construction of Scottish school notebooks were conceptualized as being part of a larger regime of

${ }^{68}$ A helpful summary of quill-making, including the dutching process, is given in the "pens" entry in Daniel Keyte Sandford, Thomas Thomson, and Allan Cunningham, The Popular Encyclopedia: Being a General Dictionary of Arts, Sciences, Literature, Biography, History, and Political Economy (Glasgow, 1836), 732-35.

${ }^{69}$ Many writing instructors demonstrated how to make a pen to their students. For a helpful written account, see the section entitled "Directions How to Make a Pen," in Andrew Lawrie, The Merchant Maiden Hospital Magazine (Edinburgh, 1779), 46.

${ }^{70}$ Tracers are described and depicted in J. Barrow, A Description of Pocket and Magazine Cases of Mathematical Drawing Instruments (London, 1792).

${ }^{71}$ Both quotations are taken from Lawrie, Merchant Maiden Hospital Magazine, 44-46 (emphasis added).

72 The first page of Fisher's Instructor, one of the most popular teaching compendia in Scotland, makes direct connection between the act of observation and the modes through which a child can read the letters of the alphabet. Fisher, Instructor (1763), 1, 5, 61. 


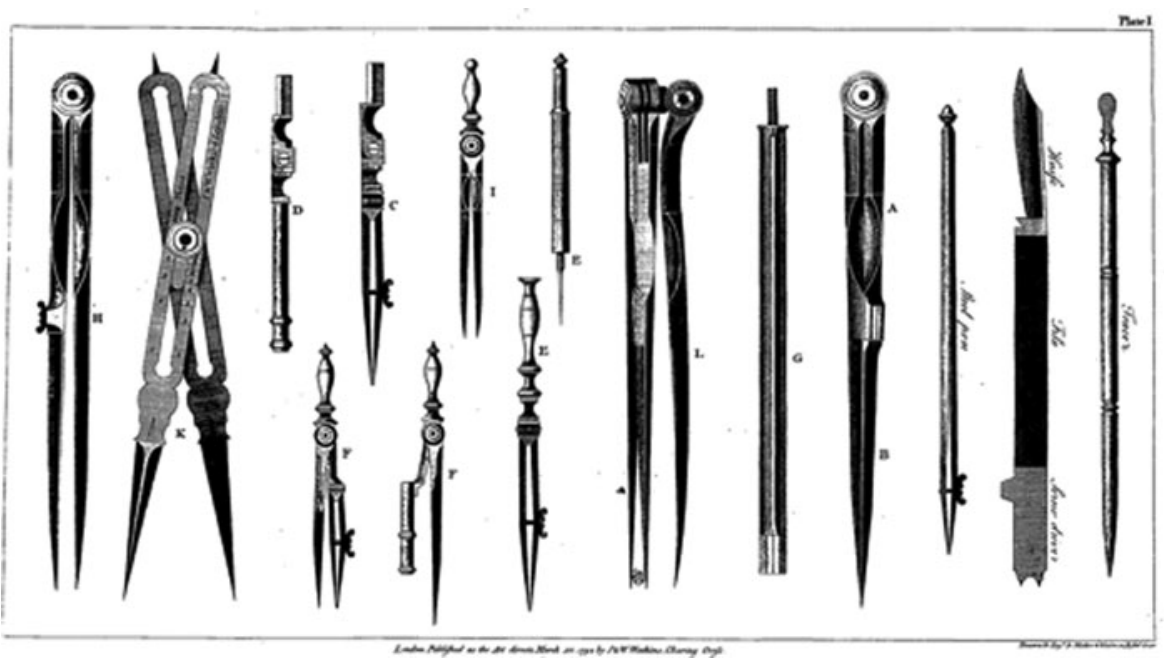

Figure 6-J. Barrow, A Description of Pocket and Magazine Cases of Mathematical Drawing Instruments (London, 1792). Plate I, at the end of the book.

observational learning that trained students to actively engage with the world around them. Learning to observe one's own writing as a note-keeper energized the kinds of visual skills that served as the starting point for understanding how the page could be mindfully schematized to fit different kinds of information. In other words, school note-keeping influenced the way that children perceived the modes through which the written page could operate as a verbal picture in motion. Like many forms of learning, note-keeping was a real-time activity.

But using a completed notebook was a real-time activity, as well, and I close this section by considering how a notebook's design influenced its future use as an informatic device. More specifically, I examine the presence of the many scanpaths that crisscrossed the notebooks made by Scottish schoolchildren.

Scanpaths were lines of sight that ran from heading to heading across the paragraphs of a page. Although now part and parcel of digital interface, they are by no means a new phenomenon. Their value was identified by a number of teachers in Britain, including Richard Grey, who called them "technical lines."73 Student notebooks were full of such lines, indicating that "sightlining" was yet another skill that underpinned the writing techniques of Scotland's student notekeepers. On the recto side of Fowler's 1780 "Schoolbook" depicted in figure 5, for example, a technical line runs straight down the left margin from the following headings: "Part II ${ }^{\mathrm{d}}$ " to "DEF I. ${ }^{\text {st" }} 1$ to "DEF II. ${ }^{\mathrm{d}}$." This navigational facet of

${ }^{73}$ Richard Grey, Memoria Technica, or, A New Method of Artificial Memory (London, 1799), 48. Grey explained how the technical line ran between typographic markers that he had developed for the word matrices in his book. The book was a popular text in Lowland Scotland. The classic modern paper on scanpaths is David Noto and Lawrence Stark, "Scanpaths in Saccadic Eye Movements while Viewing and Recognizing Patterns,” Vision Research 11, no. 9 (September 1971): 929-42. 
headings is present in many student notebooks, especially those that addressed technical topics. ${ }^{74}$

Scanpaths made it possible for students to skim their notebook pages for information by allowing the eye to jump from one heading to another. More specifically, the paths running between the headings made it possible for them (or any other future readers) to navigate from one heading to another without having to read through the entire text. Creating modules in this regular, serialized pattern took time and skill and required students to closely observe what they were designing. Writing headings in the foregoing manner was one of the main techniques that transformed a tabula folia into a tabula verba, that is to say, an efficient information management picture. It also created easily recognizable scanpaths.

In order to maintain a regular pattern of technical lines through an entire notebook, students had to enact and consistently implement a graphic nomenclature of sorts, a chirographic code that enabled them to structure the internal space of modules and matrices in a systematic manner. Every time they mapped out the framework of the pattern with graphite or lead pen impressions, and every time they attempted to write according to the codes they had selected, they were effectively transforming the pages of their notebooks into interactive visual platforms. This kind of writing, so crucial to designing a school notebook, provided Scottish students with the opportunity to learn how to structure knowledge on the page in a manner that could be accessed via the use of technical lines as they wrote and when they used the page in future.

Overall, the writing techniques required to transform blank pages into the modules and matrices of a self-organized notebook were by no means simple. The techniques reveal the rich material and visual foundations of the tabula rasa metaphor and explain why pedagogical authors such as John Locke and Dugald Stewart viewed the written page as an interactive picture.

\section{DRAWING TECHNIQUES}

Today we would seldom call a picture a "table." But, as mentioned in the beginning of this essay, during the eighteenth century, visualizations were still included under the wider designation of a tabula, a page that featured inscribed or printed knowledge. ${ }^{75}$ This means that some student note-keepers also had to learn how to transform the tabula rasa into a tabula figura. Drawing, sketching, and tracing figures increasingly played an important role in the arts, humanities, and sciences throughout Europe at this time. ${ }^{76}$ But how did Enlightenment students learn to understand the meaning and use of a tabula figura through drawing one in a notebook?

\footnotetext{
74 "Practical Mathematics," 1804, Bound MS, 14285, fols. 21-22, NLS. It is likely that this notebook was made by a student attending the Perth Academy.

${ }^{75}$ Ferguson, "Systems and Schema."

${ }^{76}$ Baxandall, Patterns of Intention; Tim Ingold, Lines: A Brief History (London, 2007); Lorraine Daston and Peter Galison, Objectivity (New York, 2007); David Rosand, Drawing Acts: Studies in Graphic Expression and Representation (Cambridge, 2002). For the eighteenth-century relationship between drawings (including pre-drawings) and pictorial intelligence, see Svetlana Alpers and Michael Baxandall, Tiepolo and the Pictorial Intelligence (New Haven, 1996); Kärin Nickelsen, Draughtsmen, Botanists and Nature: The Construction of Eighteenth-Century Botanical Illustrations (Dordrecht, 2006).
} 
Likewise, how can the "drawnness" of figures, the material and visual techniques of their construction, help us to conceptualize the ways in which student notebook drawings laid the foundation for self-directed forms of scribal performance?

Within Scotland, many educators treated drawing techniques as modes of learning. Accordingly, students were repeatedly asked to draw (and, hence, observe) figures in ways that helped them to learn concepts such as distance, magnitude, and altitude. As the Scottish pedagogue George Turnbull pointed out, in addition to rendering an object on the page, learning to "draw lines and figures upon paper," no matter how simple, was a useful knowledge-making technique. In Turnbull's view, the arts of drawing were collectively important when they operated "as a means, and not as an end; when they lead us to something else, and not when they are rested in as the principle part of instruction." 77 In many cases that "something else" was a set of linear concepts relevant to recognizing symmetry, parallelity, similarity, perpendicularity, angularity, equality, and proportionality. ${ }^{78}$

Turnbull's observation reminds us that Scottish students learned that, like the act of molding a page or the act of writing a script, the act of drawing a notebook page was a valuable real-time learning tool, a manual activity that helped learners internalize and spatially understand different kinds of knowledge. As pedagogues across Europe such as John Locke in Britain and August Hermann Franke in Germany observed, it was widely accepted that simple figures facilitated a child's powers of observation and apprehension. ${ }^{79}$ Educators held that, no matter what kind of knowledge was being represented, simplicity was a virtue.

The Scottish pedagogue Lord Kames summarized this widely held sentiment with the following advice: "Begin not to teach Euclid, till he [a student] is well acquainted with the different figures. In that view, employ him to inscribe a circle in a square, a triangle in a circle, and so on. This manual operation will be an enticing amusement: and at the same time contribute to make the demonstrations more readily apprehended." 80 Kames was communicating a view that educators should place a high value on drawing techniques as developmental learning tools. Notably, Kames, like many Scottish pedagogues, was following the lead of Locke's theory of mind that placed a high value on geometric shapes, or diagrams, that could be achieved by transforming a blank page into a tabula figura. In Locke's words, "Diagrams drawn on paper, are copies of ideas, and not liable to the uncertainty that words carry in their signification." 81

\footnotetext{
${ }_{77}$ George Turnbull, Observations upon Liberal Education, in All Its Branches: In Three Parts (London, 1742), 273.

${ }^{78}$ Linear concepts such as proportionality, similarity, perpendicularity, and parallelity are mentioned repeatedly in most geometric textbooks. See George Douglas, The Elements of Euclid (Edinburgh, 1776); Robert Simson, The Elements of Euclid (Edinburgh, 1781); William Scott, Elements of Geometry (Edinburgh, 1782); Nicolas Vilant, The Elements of Mathematical Analysis ... and A Synopsis of Book Vof Euclid (Edinburgh, 1798); Alexander Ingram, The Elements of Euclid (Edinburgh, 1799). For an informative look at how the concept of proportionality functioned as a tool in the building of geometric systems, see John West, Elements of Mathematics: Comprehending Geometry, Mensuration, Conic Sections and Spherics (Edinburgh, 1784), vi-vii.

${ }^{79}$ John Locke, Some Thoughts Concerning Education (London: Churchill, 1693), 184. Franke's use of pictures is discussed in Kelly Joan Whitmer, The Halle Orphanage as a Scientific Community: Observation, Eclecticism, and Pietism in the Early Enlightenment (Chicago, 2015), 56.

${ }^{80}$ Home, Loose Hints upon Education, 235.

${ }^{81}$ John Locke, An Abridgement of Mr. Locke's Essay Concerning Human Understanding (Edinburgh, 1767), 164.
} 
Within the wider world of children's publishing in Europe, authors steadily included more figures such as games, prints, and illustrated chapbook stories as the century progressed. ${ }^{82}$ Yet the picturesque charm of these relatively expensive images does not seem to have played a significant role in the figural forms of representation used to educate most Scottish schoolchildren, particularly those of the working and middle class who attended parish or burgh schools. In fact, such images rarely appear in school notebooks or in printed textbooks. The predominant visual forms presented in notebooks were word modules and matrices, and all the visual cues that they entailed.

Nevertheless, from the mid-century onward, a growing number of Scottish students learned to draw a notable assortment of schematically orientated figures in school subjects relevant to mensuration, geography, geometry, and, in a handful of schools, natural philosophy. Consequently, when we speak of school notebook "figures," we are speaking about a specific kind of schematic representation designed to help young learners understand how they might reduce the world to lines of measurement that, on the whole, could be used in trade, industry, land management, or other kinds of professional or military contexts.

Constructing a figure required a variety of materials and instruments. These in turn were transformed through a plethora of drawing techniques such as tracing, sketching with graphite, shading through crosshatching and smudging, stippling, pricking, grooving with trace pens, and painting with watercolors. The smoothness and regularity of the lines in notebook figures, for instance, indicates that students were constantly observing their "strokes" and "scores" to fit the kinds of paper they used and the evenness of the lines they wanted to make in their figures. The precision and lack of deviations in the strokes in many notebooks reveals that student note-keepers learned to use various instruments of draftsmanship, the most common being metal-tipped drawing pens (sometimes with a protracting pin), graphite pencils, rulers for straight lines, and compasses for circular lines. For more advanced figures, there were protractors and sectors as well. Instrument makers sold these items individually or as part of a collection that was called a "pocket case."

School notebooks from Scottish academies, burgh schools, and some grammar schools contain circles drawn first in graphite and then traced over in ink. This indicates that students were using compasses that had several interchangeable "points" for drawing or impressing different kinds of lines. More specifically, they were using compasses equipped with a "plain point" for impressions, a "pencil point" for graphite lines, an "ink point" for solid ink lines, and a "dotting point" for dotted ink lines. These instruments were sometimes included in a pocket case. For more advanced students, there was the "magazine case," which, in addition to including a wider variety of the foregoing instruments, offered calipers and a watercolor set (see again figure 6). ${ }^{83}$

Using the implements contained in a pocket case or a magazine case, student notekeepers made two kinds of figures: shapes and tableaux, both of which were made in stages with a cluster of techniques. Both were drawn schematically, but some

${ }^{82}$ Anke Te Heesen, The World in a Box: The Story of an Eighteenth-Century Picture Encyclopaedia (Chicago, 2002); Barbara Maria Stafford, Artful Science: Enlightenment Entertainment and the Eclipse of Visual Education (Cambridge, 1996).

${ }^{83}$ Barrow, A Description of Mathematical Drawing Instruments, 6-7. 
notebooks feature three-dimensional shading and colorization (mainly through water-coloring) techniques.

Shapes usually came in the form of overtly geometricized, freestanding objects around which students left a field of open, white space. The most common shapes were polygons and polyhedrons, or metrological instruments such as dials, compasses, rulers, and quadrants. ${ }^{84}$ As figures 3 and 7 show, some renderings of instruments and polyhedrons were executed with great skill. The overarching impression given by most notebook figures was that of a stylized picture of clean contour lines to which students could easily attach information.

While figures of instruments, especially rulers and quadrants, were featured in contemporary textbooks, ${ }^{85}$ it is important to note that, when viewed in reference to the process of student note-keeping, such shapes were not static entities. The act of drawing them, for instance, was a crucial element in how students learned to conceptualize them as objects. Creating a schematic form of representation endowed students with the capability to observe in real time how rectilinear and curvilinear depictions could serve as paper tools to which useful empirical or metrological information could be attached through inscription, thereby transforming the lines of the figures into different kinds of significant metrological space such as inches and degrees. ${ }^{86}$

In contrast to the stand-alone quality of freestanding shapes, tableaux usually were collections of freeform shapes such as trees, houses, ships, islands, fields, mountains, countries, and continents geometrically plotted according to a grid or angles. A good example of a tableau can be seen in the leveling scene depicted in figure 8 . Taken from the leveling section of a student notebook, the figure on the right visualises the side of a mountain reduced to a series of right angles. The collage of shapes in notebook tableaux occurred most commonly as landscapes or maps. The shapes were arranged in a manner that demonstrated the metrological relations between several objects, that is, in a manner directly relevant to leveling or gauging. Additionally, the notebooks of students who possessed advanced drawing abilities occasionally included freestanding shapes within a simple tableau. The quadrant at the bottom right of figure 3, for example, is part of a tableau that only included two other shapes: a triangle and a tree. ${ }^{87}$

Knowing how to draw relationships like parallelity or even rectilinearity could be applied to a multiplicity of real or imagined objects when students became adults. ${ }^{88}$ Once learned, the techniques helped students to conceptualize shapes as objects to which various kinds of meanings could be attached. The lines that delineated the space of a square, for example, were significant because they were proportionate,

\footnotetext{
${ }^{84}$ Metrological instruments occur in many gauging and surveying notebooks. For representative specimens, see "Practical Mathematics," fols. 6, 33, 45.

${ }^{85}$ See Fisher, Instructor (1763), and John MacGregor, A Complete Treatise on Practical Mathematics (Edinburgh, 1792), for representative specimens of the kinds of instruments included on compendia plates.

${ }^{86}$ For the cognitive links between using instruments and creating metrological knowledge, see again Livingston, Ethnographies of Reason.

${ }^{87}$ My use of the term "tableau" is based on the following studies: John Bender and Michael Marrinan, The Culture of Diagram (Stanford, 2010), 19-52; Christine Poggi, In Defiance of Painting: Cubism, Futurism and the Invention of Collage (New Haven, 1992), 86-89.

${ }^{88}$ Whitmer, The Halle Orphanage, 54-59.
} 


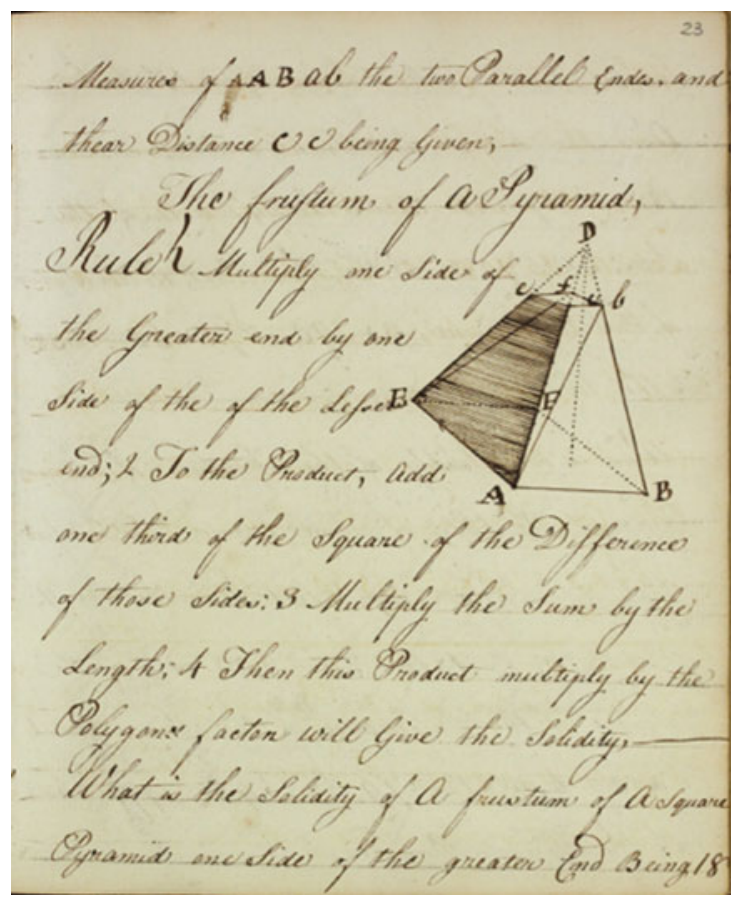

Figure 7-Robert Jackson, “Geometry Notebook of Robert Jackson, A Schoolboy,” (1788), Bound MS, NLS MS 9156, fol. 23.

perpendicular, and equal. Only once these qualities were understood could they be used to determine the area, volume, or movement of objects. Drawing techniques, therefore, implicitly imposed a set of dynamic perceptual categories that children could use to determine what was worth observing and then drawing in an image. Crucially, although the utility of a polygon or polyhedron could be viewed in the many geometric diagrams included in textbooks, those in notebooks were more powerfully internalized through the manipulation of drawing instruments and paper during the act of rendering notebook figures. ${ }^{89}$

At the time, middle-class children in Scotland were increasingly learning how to draw portraits, landscapes, and patterns for sewing. But, perhaps ironically, the acts of drawing practiced by student note-keepers reversed the visualization process promoted by avant-garde artists who believed that certain kinds of pre-drawings actually inhibited pictorial composition. Students attending the Edinburgh drawing academy of the influential landscape painter Alexander Nasmyth, for example, were introduced directly to painting techniques before they were even taught to draw.

89 The use of compasses and rulers (straightedges) as tools that generate and sustain an objective world is examined in Livingston, Ethnographies of Reason, 109-20. See also Livingston's analysis of drawing the lines and curves of Euclidean geometry in idem, The Ethnomethodological Foundations of Mathematics (London, 1986). 

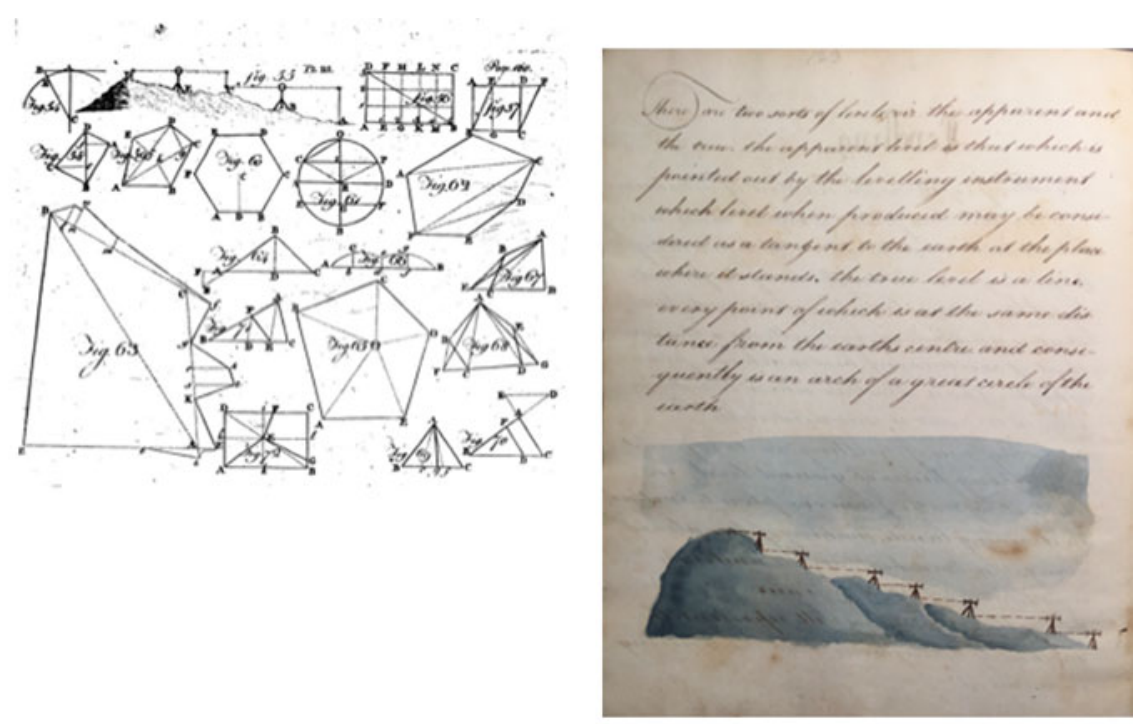

Figure 8-(Left) Alexander Ewing, A Synopsis of Practical Mathematics (Edinburgh, 1799), Plate III. (Right) Anonymous, "Practical Mathematics," (1804), Bound MS, NLS MS 14285, fol. 123. Ewing's leveling figure (top row, figure 55) did not appear next to the narrative that described it and was only a specimen on a plate of twenty other figures. In contrast, the leveling figures in student notebooks were much larger, watercolored, and appeared on the same page as the narrative that described them.

Mary (née Fairfax) Somerville, who studied at Nasmyth's academy during the 1790s, sardonically summed up Nasmyth's method in her autobiography: "I was not taught to draw, but looked on while Nasmyth painted." ${ }_{90}$ Unlike the dreamy landscapes of artists like Nasmyth, the tableaux featured in student notebooks were effectively collections of shapes that occurred in the form of countries or landmarks like mountains, houses, or forests (see again figure 8). The shapes were usually arranged according to a quadrangular frame or triangular grid, or as semi-threedimensional vignettes.

If we step back for a moment and consider even the most basic skills that students learned to transform lines into shapes and tableaux, it becomes apparent that the tabula rasa concept was further enhanced by the abilities required to make, understand, and use a tabula figura, that is to say, a notebook page that presented a figure. But many students were skilled drawers, and it is worth further exploring the techniques they used and the visual capabilities that they bestowed.

Like the figures featured in the printed mathematics textbooks used in schools, ${ }^{91}$ most notebook shapes were relatively simple in that they could be inscribed with instruments contained in a pocket case. Some students, most likely those who

${ }^{90}$ Mary Somerville, Queen of Science: Personal Reflections of Mary Somerville, ed. Dorothy McMillan (Edinburgh, 2001), 38.

${ }^{91}$ See the figures throughout Fisher, Instructor (1763); Hoppus, Practical Measure Made Easy; Ewing, Synopsis of Practical Mathematics; Panton, Tyro's Guide. 
studied with drawing masters at home or at school, used pocket-case instruments to execute advanced shading techniques that added dimensionality to geometric figures and made it easier to see overlapping surfaces and volume. As evinced in figures like the expertly crosshatched but partially translucent pyramid drawn in the 1788 "Geometry" notebook of the schoolboy Robert Jackson (figure 7), ${ }^{92}$ students taking advanced mathematics courses learned through drawing complex shapes. Likewise, in addition to depicting standard instruments of measurement, some notebooks contain detailed iterations of air pumps, common pumps, thermometers, magic lanterns, compound microscopes, camera obscuras, and prisms. ${ }^{93}$

Perhaps the most informative specimen of an instrument appears as the "figure of an horizontal dial," a common sundial, in the dialing section of James Fowler's Schoolbook. ${ }^{94}$ As evinced in figure 9, Jackson did not finish it. Its incomplete state, however, makes it easier to see how he composed it and sheds much light on the drawing techniques that students employed to make a tabula figura. Dials were important during the Enlightenment because they were used alongside compasses and the gridded globes and maps that were employed in navigation. Accordingly, textbooks not only gave instructions on how to draw them but also how to calibrate them to work in different latitudes. ${ }^{95}$ Indeed, the latitude that Fowler penned on his dial (58 degrees north) reveals that he customized it to correspond to his own location (Fodderty) in northwestern Scotland.

Fowler's dial demonstrates how students learned to understand technical instruments through sketching, tracing, and shading them on a piece of paper that was destined to become a page in a notebook. ${ }^{96} \mathrm{He}$ began by penciling a square in graphite with a ruler. Using a small compass, he then drew a graphite circle. Next, he drew radiating lines in graphite over the square and used ink to inscribe stippling dots (over the circle), a signature, the date, a latitude bearing, the four points of the compass, and numeric labels for the radiating lines. Finally, he drew a hand for the dial in the brown chalk used by painters to make pre-drawings.

Had Fowler completed the dial, he most likely would have followed the common practice of coloring its different parts with paint. ${ }^{97}$ Each step shows how the different drawing techniques were required to composite knowledge on the page-literallyin layers. Drawing the dial thus constituted a sophisticated form of graphic interface, both inside the image as well as between the image and the surrounding narrative that described the construction of the dial. ${ }^{98}$ In short, Fowler learned to understand the components of the dial as a paper tool by drawing and then labeling them.

92 Robert Jackson, "Geometry Notebook of Robert Jackson, A Schoolboy," 1788, Bound MS, MS 9156, fol. 23, NLS.

${ }^{93}$ For exemplary specimens used in the Perth Academy natural philosophy course, see I. M. (Notekeeper), "Perth Academy Notebook, Natural Philosophy," 1787, vol. 3, Bound MS, MS 14296, fols. 56-57, 77-78, 90-91, NLS.

${ }^{94}$ Fowler, "Schoolbook," fol. 134r. "Dialing" was included in many compendia, including Fisher, Instructor (1763), 313-19.

${ }^{95}$ Fisher, Instructor (1763), 314-15.

${ }^{96}$ Fisher's "dialing” sections are accompanied by a fold-out table of dials. Ibid., 319-21.

${ }^{97}$ Fisher advised his readers to cut out his dials, paste them to wood, and then paint them. Further sections explain how to make paint from household items. See ibid.

${ }^{98}$ It is worth noting here that the dial occurs at the end of several pages of narrative on various kinds of dialing. Fowler, "Schoolbook," fols. 123r-133v. 


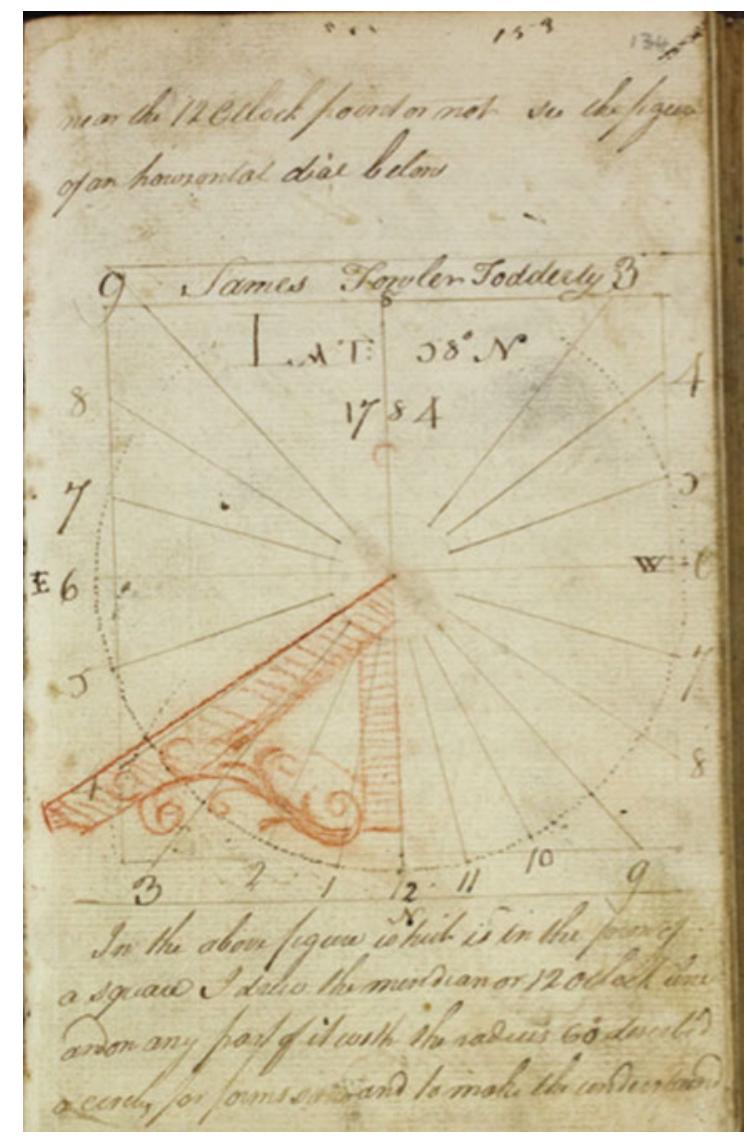

Figure 9-James Fowler, "Schoolbook of James Fowler; Strathpeffer," (1780), Bound MS, NLS MS 14284, fol. 134r.

The larger point to note here is that, like the techniques of molding and writing, the techniques of drawing evidenced in student notebooks provide a rich developmental picture of the material and visual basis of the tabula rasa metaphor. This point is also powerfully made by the maps that geography, gauging, and surveying students drew in their notebooks. In the rest of this section, I explore the kinds of capabilities that such techniques imparted and to contextualize why they are important for understanding how students used note-keeping to conceptualize linear forms of knowledge.

The "Maps" school notebook created by Jemima Arrow in 1815 provides us with fine examples of framed maps. ${ }^{99}$ These were visualized with techniques likely learned from a private tutor or from a teacher working at one of the private schools for girls that emerged in Scottish cities during the late eighteenth century. Arrow's notebook contains hand-drawn maps of France, the United Provinces, Germany, Italy, and

99 Jemima Arrow, "Maps,” 1815, Bound MS, MS14100, NLS. 
Turkey (figure 10). ${ }^{100}$ For each country, Arrow drew two maps. The first contained no labels or names and was drawn in graphite lines, then traced over with ink. For the second map, she turned the page and drew (or possibly traced) the same image, but she went further by watercoloring its borders, printing an alphabetical heading inside each country, and writing a legend (a matrix) on the opposite page that matched the headings with names of countries. She employed this two-step technique for all five countries in the notebook.

Aside from learning the geography of several Mediterranean countries, drawing and labeling maps with these kinds of techniques inculcated what Matthew Edney has called a sense of "map-mindedness." the exercise afforded two very useful kinds of mnemonic devices. The first, a blank map, could be used to test her memory without recourse to the legend. The second, a labeled map, could be used to test her memory against the legend of the facing page.

The notebooks of students who took surveying courses feature tableaux executed with more advanced drawing techniques, taking the pictorial transformation of the tabula rasa into a tabula figura to a more complex level. Many of the notebooks contain maps depicting different kinds of terrain and property configurations reduced to geometric shapes through triangulation. ${ }^{102}$ The neatness of such maps intimates that, like Arrow, surveying students probably learned drawing techniques by copying exemplars. Occasionally students made less stylized "on-site" maps as well, often with graphite lines peeking out from behind their overlaid ink strokes. These maps usually depict a local property and were likely made as final assignments. ${ }^{103}$

Some property maps that occur in notebooks were specially made for the student. These occur in notebooks overseen by private tutors who tailored the surveys to fit the needs of their tutees. For example, in an anonymous student notebook kept from circa 1809 to 1812, most of the questions, as well as most of the maps, were based on sites in the Yarrow area of southern Scotland. ${ }^{104}$ In addition to learning how to reduce a landscape to mathematical observations, making survey maps of this nature helped students become ecological observers. ${ }^{105}$

A variety of gauging and leveling scenes also appear in school notebooks. Instead of being arranged according to a quadrangular frame or triangulation, these were structured according to a variety of angles that served to determine the distance between objects. The most detailed specimens occur in tableaux rendered by students

100 Ibid.

${ }^{101}$ Matthew H. Edney, "British Military Education, Mapmaking, and Military 'Map-Mindedness' in the Later Enlightenment," Cartographic Journal 31, no. 1 (June 1994): 14-20. See also Charles W. J. Withers, "The Social Nature of Map Making in the Scottish Enlightenment c. 1682-c. 1832," Imago Mundi 54, no. 1 (January 2002): 46-66.

${ }^{102}$ A sample of notebooks that treat surveying and gauging include "Practical Mathematics"; "Perth Academy Notebook," c. 1790, Bound MS, MS 14291, NLS; "Surveying Journal and Accounting Ledger," 1809-1812, Bound MS, MS 14283, NLS.

${ }^{103}$ Surveys of the Perth River occur in notebooks made by Perth Academy students. For two examples, see "A Plan of the North Inch of Perth," in "Practical Mathematics," fol. 121, and "N. Inch of Perth," in "Perth Academy Notebook," c. 1790, fol. 64v.

104 "Surveying Journal and Accounting Ledger."

105 Stephen H. Spurr, "George Washington, Surveyor and Ecological Observer," Ecology 32, no. 3 (July 1951): $544-49$. 


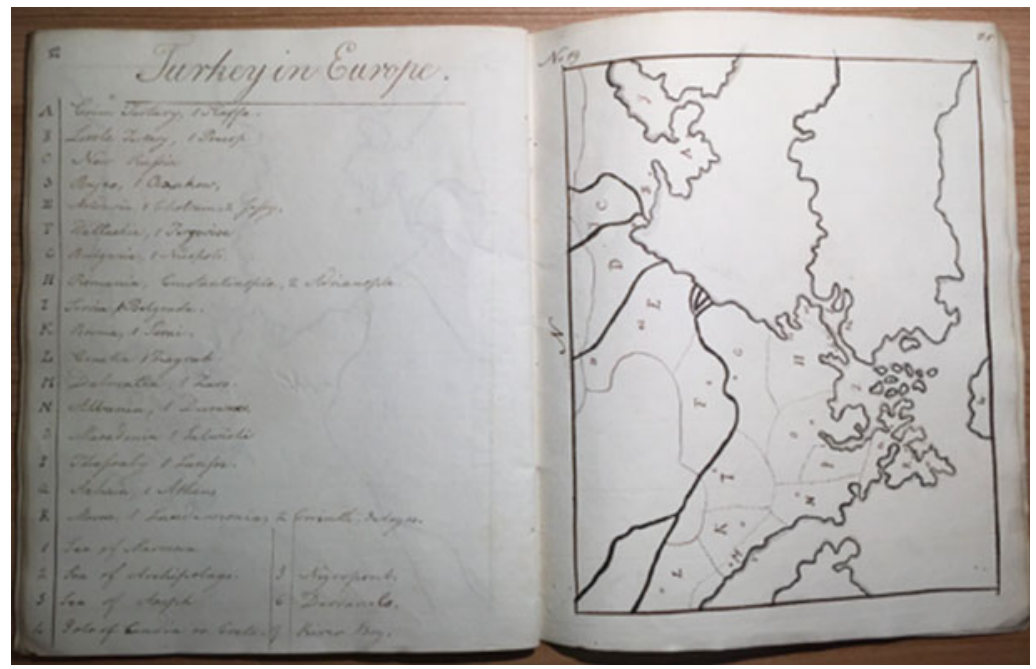

Figure 10-Jemima Arrow, "Maps" (1815), Bound MS, NLS MS 14100, fols. 34-35. Folios 32 and 33 contain an unlabeled map of "Turkey in Europe" and folios 34 and 35 (below) feature a labeled map. Grey watercolors were used to shade the coastlines in both maps.

attending Perth Academy during the last decades of the eighteenth century. ${ }^{106}$ Figure 8 shows that some of them lavishly illustrated their notebooks with expertly designed landscapes to accompany various mensuration exercises used in gauging and leveling. 107

Like the maps in Arrow's geography notebook, gauging, leveling, and surveying tableaux appear alongside the script that describes them. The made-to-order nature of this format is complemented by the fact that, while popular mensuration textbooks such as Alexander Ewing's Practical Mathematics or Alexander Ingram's New Seaman's Guide included plates that featured only a handful of similar vignettes, student notebooks include one for every problem, making it easier to see, and hence learn, how gauging, surveying, or leveling could be applied to everyday situations (see again figure 8$) .108$

While the drawing techniques used to make tableaux were more nuanced than those required to make freestanding shapes, students learned a number of techniques to employ across both forms of representation. As intimated in my observations about the narrative descriptions that accompanied shapes and tableaux, the techniques of drawing often interacted in real time with the techniques of writing

106 I. M. (Notekeeper), "Perth Academy Notebooks"; "Perth Academy Notebook," 1780s-90s, Bound MS, MS 14291, NLS.

107 "Perth Academy Notebook," 1780s-90s.

108 Compare, for example, the leveling figures in Alexander Ewing, A Synopsis of Practical Mathematics (Edinburgh, 1799), plate 3 and "Practical Mathematics," fol. 123. Ewing's Synopsis was a popular text in Scotland and had numerous reprintings in the 1790s alone. Alexander Ingram, The New Seaman's Guide, and Coaster's Companion (Edinburgh, 1800). 
words. Put another way, the tabula figura often had to be combined with elements of the tabula verba. Aside from the occasional presence of a stylized map, the geometric and schematic nature of figures meant that they were rarely self-explanatory. Students therefore seldom included them in school notebooks without a written text that explained what they were meant to represent. The text was often cued to the figure through the use of literary technologies such as alphanumeric headings, labels, or prose written on or beside the figure.

Examples of this common practice are offered in figures 3 and 10, but the composition of Robert Jackson's pyramid in figure 7 is particularly striking. Close examination of the strokes and the modes through which it was skillfully plotted adjacent to its verbal description further reveals that students were actively designing the space of the page by plotting words around figures. From the way in which the words flow evenly around the pyramid, Jackson clearly drew the image first and then added the narrative. This technique required him to pre-plan the layout of the page, and it enabled him to create a seamless visual integration of script and figure.

Many combinations of script and figures in school notebooks were executed within a word module, which meant that students could skim the headings to find them once the notebook had been completed. Since notebook figures needed to be positioned within or nearby textual material that explained what they meant, the success of the entire visualization depended upon the compositing techniques that students used to lay out their notebook pages as modules. Far from being a unique occurrence, the meanings of many Enlightenment figures used outside the world of education, particularly those circulating in scientific or technological contexts, were dependent upon the descriptive texts that accompanied them. ${ }^{109} \mathrm{By}$ jointly writing words and drawing figures, student note-keepers were learning how to mitigate the visual limitations of figural representation.

When we consider all the drawing techniques evinced in student notebooks, it becomes clear that, like the modes of interface required to execute molding and writing techniques, the modes through which students composited a figure enrich the tabula rasa metaphor by adding a hitherto unnoticed developmental layer, one in which the blank page functioned as a starting point for an interactive process of representation and learning.

\section{CONCLUSION}

In this essay we have considered the metaphor of the tabula rasa in light of the dynamic molding, writing, and drawing techniques required to transform blank sheets of paper into a student notebook, that is, a purposeful and user-friendly artifact. We traced these techniques in reference to the material and visual conditions required to make a page as a tabula folia, script as a tabula verba, and an image as a tabula figura. The possibilities inherent in these forms, and the capabilities entailed in the many techniques required to make them, reveal a developmental richness of the

\footnotetext{
${ }^{109}$ On the long-standing reciprocal relationship between printed figures and words, see Horst Bredekamp, Vera Duenkel, and Birgit Schnieder, eds., The Technical Image: A History of Styles in Scientific Imagery (Chicago, 2015). For manuscripts, see the captions of the figures in Daston and Galison, Objectivity, 84-98.
} 
tabula rasa that far exceeds the notion of blankness that scholars have frequently attributed to it. Rather, the metaphor reflected a much wider meaning, one that drew upon the considerable amount of time, effort, materials, and concentration inherent in the techniques required to make a page, codex, module, matrix, shape, or tableaux. This meaning rendered the tabula rasa and, hence, the mind, a longitudinal entity, something constructed in stages over time and dependent upon a wide set of preconditions made possible through students' abilities and the resources afforded by their institutional contexts.

This essay has further revealed that, in addition to using textbooks to establish what students were supposed to be learning, examining notebooks allows us to reconstruct a more faithful picture of what students were doing while they learned. Indeed, making notebooks helped students think more efficiently. That the visual, material and conceptual skills afforded by the tools and techniques of note-keeping were being experienced at such an early age also reveals that the cognitive development of Enlightenment students was directly affected by the forms of interface provided by the notebook as a learning device. From a cultural perspective, the techniques of note-keeping underpinned essential modes of information management that made it possible to represent knowledge on paper during the Enlightenment. Student notebooks played a core role in the conceptualization and transmission of such skills.

Finally, the histories of the Scottish Enlightenment written over the past century have repeatedly emphasized that the graduates of Scotland's schools and academies often went on to extraordinary careers, both inside Scotland and throughout the British Empire. We have encountered the student notebooks of several personalities who participated in this wave of intellectual achievement, particularly the orientalist William Erskine, the politician Lord Henry Brougham, and the novelist Sir Walter Scott, all of whom pursued writing careers that were fundamentally dependent upon the techniques of note-keeping. But of course, as the variety of notebooks discussed in this essay so richly reveals, these authors represent a tiny fraction of the students educated by Scotland's schools, academies, and tutors. In the seemingly ordinary notebooks of students such as James Fowler, Jemima Arrow, Robert Jackson, James Dunbar, and scores of other anonymous students, the real flavor and variety of Scotland's educational system emerges. In many respects their very existence speaks to the system's success in teaching a wide variety of students to use a notebook as a powerful paper technology. 